\title{
Dam Safety: Monitoring of Tailings Dams and Safety Reviews
}

\author{
Nasrat Adamo', Nadhir Al-Ansari², Varoujan Sissakian ${ }^{3}, J_{a n}$ Laue $^{4}$ \\ and Sven Knutsson ${ }^{5}$
}

\begin{abstract}
The awareness to tailings dam safety monitoring and reviews has increased by the catastrophes resulting from failures of such dams worsened by increasing tailings waste and construction of larger dams. The losses born by the mining industry from high costs of compensations and environmental rehabilitation work have brought this matter into focus. In the present article the need for safety monitoring programs of tailings dam is highlighted and mode of failures and factors leading to them are described. Basic principles of such programs are investigated with all phenomena needing observation described and their impacts explained. As in conventional dams this work is carried out by visual inspections and use of similar methods and instruments. In similar manners in both types of dams' observation and measurements are done for measuring seepage water quantity and quality, phreatic surface level and pore pressure and total earth pressure values in addition to deformation measurements; and all are done by similar devices and methods such as weirs, piezometers, inclinometers, settlement plates and geodetic surveying. Basic differences between safety monitoring systems of the two types of dam, however, are presented in a tabular form. The continuity of safety monitoring of tailings dams is emphasized not only during the long construction phase but also after that in the abandonment and closure phase which can last indefinitely in order to watch for possible adverse effects on the environment and ecosystem due to the winds eroding and carrying of poisonous tailings contents, in addition to
\end{abstract}

\footnotetext{
${ }^{1}$ Consultant Dam Engineer, Sweden.

2 Lulea University of Technology, Lulea 971 87, Sweden.

${ }^{3}$ Lecturer, University of Kurdistan Hewler and Private Consultant Geologist, Erbil.

${ }^{4}$ Lulea University of Technology, Lulea 971 87, Sweden.

${ }^{5}$ Lulea University of Technology, Lulea 971 87, Sweden.
}

Article Info: Received: September 7, 2020. Revised: September 17, 2020.

Published online: September 28, 2020. 
contaminated seepage water entering surface water streams and ground water. Justifications for using real time monitoring systems for recording and transmitting all data to the control center are presented with emphasis given on savings in both labor and time and need for the discovery of warning signs enabling raising earlier the alarm of possible failure or incident and the early taking of preventive measures. In this article it is argued that, in spite of the large investment of installing and running cost of comprehensive dam safety monitoring systems in tailings dams, such costs are justified as they form only a small percentage of the total investment in the tailings facilities projects, and may save huge costs if failure does happen. Such systems may be considered as an additional insurance against such events.

Keywords: Tailings dam, safety monitoring, environment, ecosystem, visual inspections, instrumentation, deformation, seepage, phreatic surface, pore water pressure, total earth pressure, settlement, inclinometer.

\section{Introduction}

In the reported 18,000 tailings dams around the world, the failure rate of such facilities in the past 100 years is estimated at $1.2 \%$. The failure rate of the traditional water storage dam is $0.01 \%$ [1]. The likelihood of Tailings dams' failures and accidents is more than 10 times than other conventional water retaining dams. Operating a tailings dam involves risks that need to be identified, quantified and mitigated. On average, three of the world's 3,500 tailings dams fail every year [2]. Statistics from available data shows that failures due to unusual rain increased from $25 \%$ pre2000 to $40 \%$ post 2000 due to the changes in climatic conditions, particularly at mine sites close to the seas and/or located in equatorial regions that have received high precipitations. The failures due to poor management accounted for $10 \%$ and $30 \%$, respectively, for the same two time periods.

A comparison of the two time groups reveals that failure in dams of up to $15 \mathrm{~m}$ height increased from $28 \%$ to $30 \%$ whereas failure in dams with heights between $15 \mathrm{~m}$ to $30 \mathrm{~m}$ increased from $21 \%$ to $60 \%$. The increase in failure of dam heights may be attributed to the combined effect of rapid dyke construction along with poor monitoring [3].

Rico et al., (2008) points out that tailings dams are more prone to fail than water storage dams due to some unique characteristics, including:

(i) Embankments built with residual material from mining activities.

(ii) Raising of the dam in multi-stages in order to increase storage capacity.

(iii) Lack of regulations and design criteria.

(iv) Continuous necessity of monitoring in order to assure the dam stability; and

(v) High cost of maintenance after the mine closure [4]. 
Keeping the tailings pond safe and stable is the most challenging task in the entire mining process. The following points are the reasons why tailings dams are more susceptible to damage than other types of water storage structures:

(i) Embankments constructed with soil, coarse waste, and residual materials from the mining operations.

(ii) The number of wastewater increases as the height of the tailings dam increases.

(iii) Lack of reasonable regulations on design standards; and

(iv) The cost of monitoring the tailings dam is high during mine operation and closure [5].

Tailings' dams failure can results from several mechanisms. These mechanisms include seepage, foundation failure, overtopping, and earthquake. Considering the serious damages caused by tailings dam breakage, it is important to understand the main reasons and mechanisms for their failure, and adopt all possible means of enhancing their safety.

Major causes of Tailings' dams instability can result from:

(i) Seepage and internal erosion.

(ii) Poor foundation conditions.

(iii) Overtopping.

(iv) An earthquake effect causing static and seismic instability, and

(v) Other reasons such as mine subsidence, structural, external erosion.

\section{Need for Monitoring and safety Reviews for Tailings Dams}

The integrity and safety of a mine tailings dam is dependent on conservative design, diligent operation, and continuous, cost-effective monitoring. Geotechnical designs can be improved by increasing resistance factors; however, even dams with conservative characteristics may experience unexpected failure due to the presence of unidentified geologic features, abnormal weather patterns, seismic shock, and the inherently variable quality of a construction project that spans multiple decades and technological paradigm shifts. Diligent, well trained operators and a reliable monitoring system are therefore critical for failure prevention and loss reduction in the face of known and unknown unknowns. To this end, an adequate monitoring system should highlight the problematic behaviors that could lead to tailings dam failure with advanced warning. Experts in the field remind us that: "For any engineer to judge a dam stable for the long-term simply because it has been apparently stable for that long period of time is, without any other substantiation, a potentially catastrophic error in judgment" [6].

If any conventional storage dam during its operation is compared with the same hazard potential tailings dam located in a remote area during the closure phase, then very few dam safety guidelines, if any, differentiate in a meaningful way between such dams when stating dam safety program requirements. And yet, these 
requirements would most likely be significantly different. For instance, the conventional dam could be seen every day with surveillance walk-overs by site personnel or carried out on a weekly basis, while the tailings dam may be seen once a year only. Or, the conventional dam would be operated for some economic advantage such as flood control or power generation, while the tailings dam would not. Or, an emergency preparedness and response plans as well as a warning system could exist and be readily implemented for the conventional dam, while for the tailings dam such plans would not exist or, as a minimum, have different meaning and certainly different response protocols. Monitoring of contaminated groundwater would not be relevant to safety evaluations of the conventional dam, but may very well are required for tailings' dams. The list of such differences can be extended well beyond these sample examples.

The frequency and the extent of dam inspections and safety reviews must account for the practicality of the implementation of dam safety program. In many cases the extent and, possibly, the frequency of dam safety inspections would have to be more intensive in the case of a tailings dam during closure phase, 'compensated' by a lower frequency of dam safety reviews.

The frequencies of dam safety surveillance by site personnel, inspections and reviews recommended in dam safety guidelines often seem rather arbitrary, or customary at best. Yet, having a rationale for such frequencies may be highly desirable where the associated costs are high; like in the case of a remotely located closed tailings facility. At least in some respects such a rationale can be developed. As an example, one of the factors that might support specifying the frequency of dam safety reviews is the anticipated "possible" change in meteorologic or seismic database.

For instance, on a project in Canadian Arctic it was shown in 1995 that there was a definite cooling trend while, after extending the database by 7 years, it was concluded in about 2000 that a clear warming trend has been occurring at the site. As another example, on a project in British Colombia Province hydrologic designs had to be revised in 1998 after the original database was expanded by additional 7 years' precipitation records. Alongside some other factors, such time periods may guide the frequency and, possibly, the extent of safety reviews for tailings dam during the closure phase. Obviously, the importance of climate warming or precipitation data will vary from site to site.

In terms of seismicity, for example in Canada, there has been a continual upward revision to the National Building Code of Canada seismic hazard maps and seismic ratings every five to ten years, showing remarkable increases in peak ground acceleration for infrequent seismic events in almost all regions of Canada; the last update was made in 2015 [7]. While an operating conventional dam may see one or two such major revisions, a closed tailings dam will be subject to changes in meteorologic and seismic databases for any concept of the foreseeable future. Having a focused guideline would be most useful to set up a framework for deriving a site-specific safety program for each tailings dam during the raising phase and in in the closure phase $[8,9]$. 
Monitoring of the tailings dam site during and after the mine closure is essential to evaluate the performance and effectiveness of the closure measures. The nature and duration of post closure monitoring depends highly on the nature and size of the operation and may continue for decades after the mine closure. On the basis of the information collected during monitoring, decisions related to further actions on the closed/rehabilitated mine sites can be made. The objectives of monitoring aim at securing proper mine closure. Therefore, a process of gathering information routinely, systematically, and purposefully for use in decision making is needed. The different closure objectives i.e. attaining physical, chemical, and biological stability and also having control over socio-economical influences, need different monitoring parameters that depend on site specific conditions. Technologies to be used in monitoring must be decided site-specifically at each tailings dam site after a thorough evaluation of their suitability [10].

\section{Failure Modes of Tailings Dams and Safety Monitoring Requirements}

Possible failure modes in tailings dams have to be recognized in any dam safety study. Parameters leading to any of them have to be defined and proper safety monitoring procedures have to be exercised in order to eliminate possible dangers of any failure and their consequences.

Key failure modes have been identified by the U.S. Committee on Large Dams (USCOLD) and the number of failures attributed to each mode is summarized from 106 incidents in Figure 1 [11].

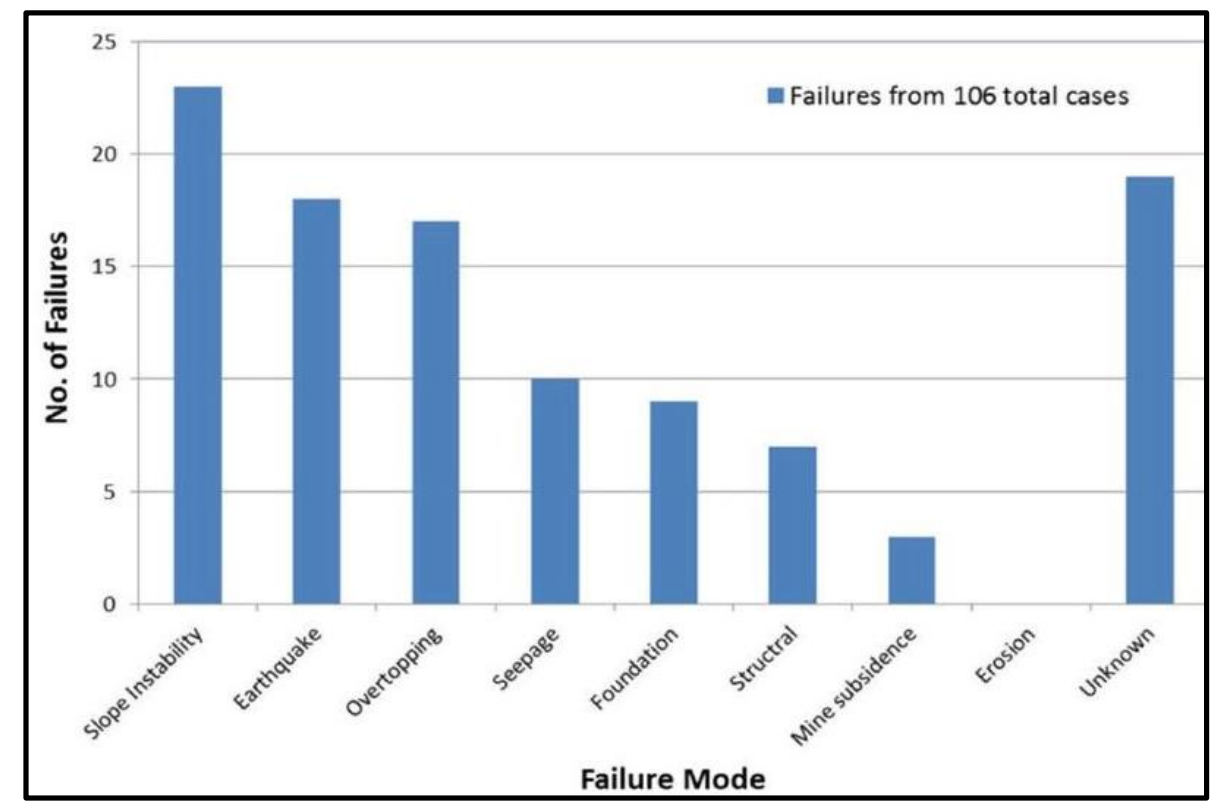

Figure 1: Failure modes of tailing dams and frequency distribution [11]. 
Slope instability failures, earthquake-induced failures, and failures owing to overtopping of the dam crest are identified as the top failure modes, while seepage, foundation, structural, and mine subsidence issues preceded fewer incidents. It should be noted at this point, however, that there is likely bias at work in these statistics as slope failures, earthquakes, and overtopping events are more easily identified in retrospect, and thus more readily attributed to the failure, than less conspicuous phenomenon like seepage, foundation instability, and internal structural deficiencies. Furthermore, it is recognized that this data represents the primary failure mode (i.e., that which resulted in a loss of containment) and that other minor modes and underlying mechanisms may have also contributed to ultimate failure. For example, the effect of elevated water held behind the tailings dam can contribute to a significant failure initiated by slope instability, overtopping, and seepage combined [12] and incipient slope failures very rarely occur without some deformation or surface expression.

An updated study carried out in 2019 shows different frequency distribution of failures and their reasons as highlighted in Figure 2. This may be due to more understanding of dam failures attributed to better monitoring, more use of instrumentation and wider reporting of failures cases of tailings dams during the last in the last 100 years.

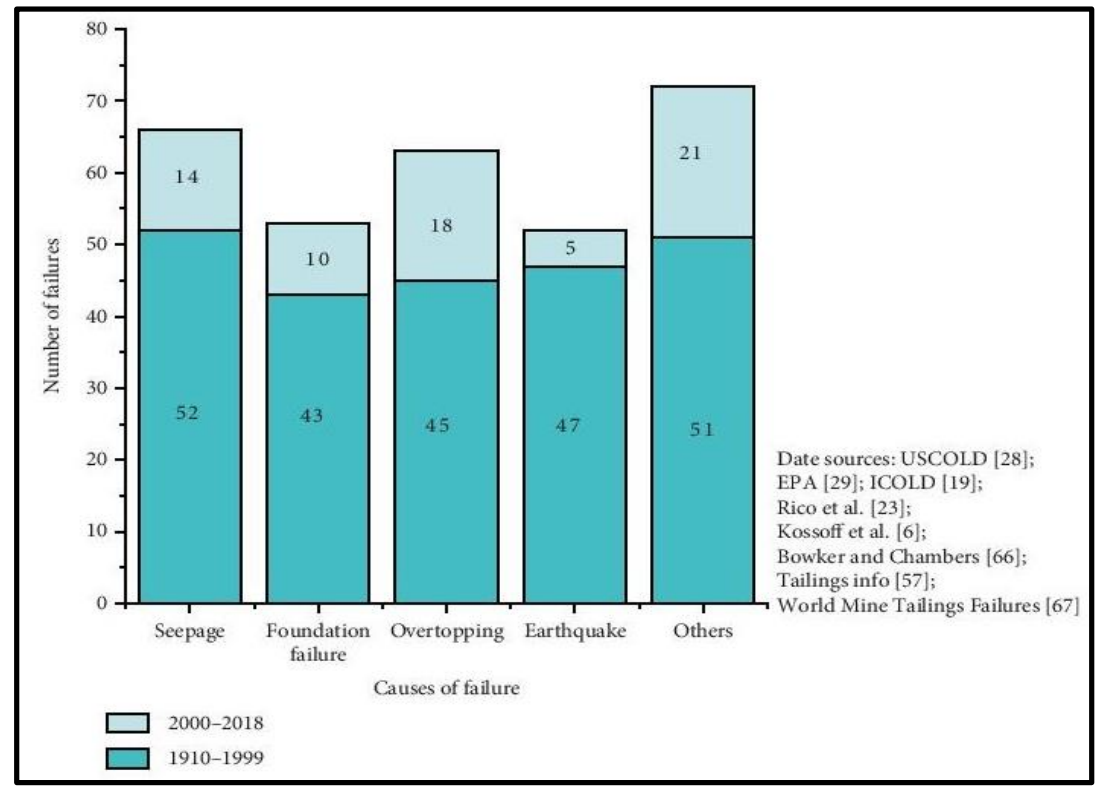

Figure 2: Failure modes of tailing dams and frequency distribution [13]. 
One scholar divided the causes of tailings dam breakage into 11 categories, namely, seepage or piping, foundation failure, overtopping, seismic liquefaction (earthquake), mine subsidence, unusual rain, snowmelt, structural, slope instability, maintenance, and unknown cause. But many accidents are the result of a combination of multiple causes, and this classification has some overlapping parts, such as unusual rain, snowmelt, and overtopping. According to the main cause of tailings dam failure, the accident percentage of seepage, foundation failure, overtopping, earthquake, and others, are respectively, $21.6 \%, 17.3 \%, 20.6 \%, 17.0 \%$, and $23.5 \%$. It can be seen from the collected data that extreme weather causes serious damage to the safety and stability of tailings dams. As human activities cause climate warming, the tailings dam failure ratio caused by extreme weather may gradually increase. It can be seen from the collected data that extreme weather causes serious damage to the safety and stability of tailings dams. As human activities cause climate warming, the tailings dam failure ratio caused by extreme weather causes serious damage to the safety and stability of tailings dams. As human activities cause climate warming, the tailings dam failure ratio caused by extreme weather may gradually increase [13].

As failure investigations become more forensic in nature, our understanding of the interdependencies of the tailings dam system and the complexity of failure mechanisms become more apparent. The considerable number of unknown failure modes in Figure 1 and even in Figure 2 is indicative of a systemic, underdeveloped monitoring culture, a lack of established industry-wide best practices, and inadequate post-failure investigations. Unfortunately, a root cause analysis may indicate complacency or ignorance within the organization and its shareholders resulting in a lack of committed resources.

Tables 1 and 2 summarize the relationship between the possible failure modes and opportunities to reduce the risk of failure. Note that earthquakes and seismically induced failure is difficult to mitigate over any meaningful timescale and therefore earthquake-exposed sites must rely heavily on the design parameters and emergency response planning.

All known failure modes can be monitored and reasonably predicted given adequate information and an understanding of the expected behavior of the system. Table 1 enumerates several parameters of interest, changes in which are characteristic of behavioral changes in the dam system.

Table 2 enumerates several parameters of interest, changes in which are characteristic of behavioral changes in the dam system. The identification of undesirable behaviors is key to assessing the risk of failure [14]. 
Table 1: Failure modes and opportunities to reduce risk

\begin{tabular}{|llll|}
\hline Failure Mode & Design & Operation & Monitoring \\
\hline Slope instability & $\checkmark$ & $\checkmark$ & $\checkmark$ \\
Earthquake & $\checkmark$ & & \\
Overtopping & & $\checkmark$ & $\checkmark$ \\
Seepage & $\checkmark$ & & $\checkmark$ \\
Foundation & $\checkmark$ & & $\checkmark$ \\
Structural & $\checkmark$ & $\checkmark$ & $\checkmark$ \\
Mine subsidence & $\checkmark$ & $\checkmark$ & 2 \\
Unknown & & & \\
\hline
\end{tabular}

Table 2: Failure modes and corresponding monitoring parameters

\begin{tabular}{|c|c|}
\hline Failure mode & Monitored parameter and behaviour \\
\hline Slope instability & $\begin{array}{l}\text { Displacement, rotation, settlement, pore } \\
\text { pressure change, tension cracks }\end{array}$ \\
\hline Earthquake & $\begin{array}{l}\text { Ground acceleration, pore pressure change, } \\
\text { settlement }\end{array}$ \\
\hline Overtopping & $\begin{array}{l}\text { Freeboard change, pore pressure change, } \\
\text { seepage flux }\end{array}$ \\
\hline Seepage & $\begin{array}{l}\text { Seepage quantity and quality, settlement/ } \\
\text { sloughing }\end{array}$ \\
\hline Foundation & Displacement, rotation, tension cracks \\
\hline Structural & $\begin{array}{l}\text { Displacement, tension cracks, seepage (core } \\
\text { failure) }\end{array}$ \\
\hline Mine subsidence & Ground acceleration, settlement \\
\hline Erosion & $\begin{array}{l}\text { Effluent quantity and quality change, } \\
\text { surface elevation changes }\end{array}$ \\
\hline
\end{tabular}

In summary, the main mechanisms behind tailings dams' failures are clearly defined and they involve; seepage, foundation failure, overtopping, and earthquakes, as well as other mechanisms of the classic examples for tailings dam failures. Proper understanding of these, together with, sufficient supervision and good management of the operation of the facility help eliminate the causes of such failures and accidents.

It is not difficult to infer that each tailing dam failure involves engineering and human factors, and that these factors can be eliminated by; proper design and management procedures, stringent observations and measurements of dam behaviors and responses. 
Finally, the availability today of wide range of modern measuring instruments and safety monitoring procedures can be considered as valuable assets in checking out the design, improving the performance of the required safety checks, which can come out with recommendations to safeguard the dam from possible adverse conditions.

\section{Basic Principles of Tailings Dams Safety Program}

\subsection{Requirements}

Any rational Tailings Dam safety program has to satisfy basic requirements if it is to give the anticipated results of avoiding incident and accident in such high investment projects. These requirements are explored in the following points;

\section{i. Continuity}

Surveillance is an essential element of the observational approach to design and construction that is so ideally suited, and so frequently applied, to tailings dams. Many tailings dam failure modes are preceded by warning signs that can be readily detected well in advance with a proper dam surveillance program. If the warning signs are promptly detected, and appropriately appreciated, time is available for the implementation of remedial measures. For many of these detectable failure modes, a good dam surveillance program, in concert with emergency preparedness and response plans, represents a highly cost-effective, proactive risk management tool relative to the options of a failure or an unnecessarily excessive and expensive degree of design conservatism. It does not however provide a means of safely stewarding a facility whose design and/or construction is flawed. Continuity of monitoring and surveillance of the facility is essential part of the successful and good management of tailings facilities including the dam, the pond and all other ancillaries. Need for rational safety monitoring program is established from the inception of the project and continuous long after its closure. Any meaningful safety monitoring program of tailings storage should be considered as an ongoing process covering the life cycle of the facility and it shall be carried out in all phases of its life.

Safety monitoring programs should be carried out by routine visual inspections, installing and regular reading of instruments and devices set for this particular objective, and by the appraisal of all the collected data by experienced engineers in safety reviews. Such safety reviews aim at the determination of the need for any further action to improve safety level of the tailings facility.

Therefore, any meaningful dam safety program has to be considered as a long chain of continuous activities, carried out in successive stages and extending over very long time which may last for decades.

\section{ii. Phases of the Safety Program}

Phases of safety program cover necessarily the complete life cycle of the facility from the planning stage of opening the mine, through the exploitation phase, and until post closure when all the wastes are deposited in the completed tailings dam. This last requirement is to ensure keeping the environment free from any 
detrimental effects of the deposits, and to detect, and remove, any danger to settlements, people life and their wellbeing. Actions needed in each of these phases may be summarized in the following lines.

\section{a) At the preconstruction phase}

At this phase, the method of raising the dam is determined and all possible environmental impacts on the surrounding areas have to be studied carefully. A complete file of past hydrologic and climatic conditions data at the site has to be accumulated including rainfall and snow fall information. These data are to be used as base line to compare for any future changes and possible consequence on the dam or on the pond. Projections of such data over the expected life cycle have to be estimated.

Changes on ambient ground water and surface water conditions have to be observed and kept to the absolute minimum. Therefore, at this preliminary stage ground water levels and water quality information have to be collected, and this has to continue during the service life of the project by the use of piezometers drilled for such purpose. These piezometers should be designed and installed as water sampling stations for taking water samples to be analyzed for any hazardous change in quality arising from increased content of harmful chemicals and heavy metals which can develop due to seepage water originating from the pond into the ground water table. Surface water courses have to be monitored for possible discharge variations and possible flooding of the tailings dam and the tailings pond, and may require diversion of the courses of some of them. Collecting of such data at this stage is essential to carry out also Environmental Impact Study of the facility and to updated it in the future. This surveillance has to follow guidelines prepared by the designer which define the objectives, frequency and the means of such surveillance.

\section{b) At the construction phase}

The construction phase of any tailings dam covers the whole exploitation period of the mining facility which may extend for decades depending on the size of the facility and production rates. It is essential, therefore, to keep the tailings dam, the pond and all ancillary works under strict safety control if incidents or failure are to be prevented. This is done by safety surveillance through routine visual inspections, recording the readings of the installed instruments, and observing and documenting any anomaly in behavior which has to be reported immediately to the management for prompt action.

This procedure is the only mean to discover problems at an early stage and find solutions to ensure safety and avoid failure. The quick response to any threat that may appear during this phase by taking the appropriate remedial measures is of extreme importance.

Safety surveillance of tailings dams' is done in similar ways as for conventional dams and it follows guidelines drawn by the designer.

Use of instrumentation systems is normal in dam safety assurance programs of tailings dams during this phase, and it is similar in many ways to those used for conventional dams. Differences, however, do exist and these differences are 
detailed later on. More is said also on the types of measurements and the factors contributing to tailings dams' safety.

\section{c) At Closure and Rehabilitation Phase}

Immediately after closing down the mining facility, the rehabilitation phase begins and the question of the required monitoring of the completed tailings dam has to be addressed.

Depending on the particular details of the individual dam, various works may be carried out, such as the protection of the surfaces from water and wind erosion by covering with clean mine pit overburden or other available earth or rock materials. This may be supplemented by humus soil, sown with suitable crops. If toxicity is high, the crops may not be suitable for consumption, but if it is within admissible limits or reduced to such limits after a certain period, then it may be used for agricultural purposes. Slopes might be covered with earth grasses and afforested with rapidly growing trees and bushes, although care should be taken to ensure that surface runoff is intercepted by ditches and prevented from entering the tailings ponds. The tailings dam should be protected against extreme floods, and measures taken for complete interception and recycling of seepage water.

The monitoring usually required during the initial stages of rehabilitation includes measuring the seepage water discharge for its solids content, chemical composition and $\mathrm{pH}$ values, the position of the phreatic surface to confirm that it is safe within the impoundment and clear from the downstream slope of the dam.

Pore pressure conditions within the impoundment can be used to indicate consolidation, and should show up the effect of the drains, giving a clear indication of their effectiveness. Hydraulic measurements will indicate the effectiveness of the diversion and spillway facilities that have been provided, and settlements need to be checked to ensure that the hydrologic arrangements are not being nullified by the development of adverse gradients.

The measurements and the observations should be carried out in the same way as the last years of operation. The same parameters are measured, i.e. those related to the stability of the dam, the erosion of the slopes and the protection of the environment. The same instruments are used so long as they continue to give reliable results, after the long period of operation.

The frequency of observations and measurements usually becomes progressively less during the rehabilitation phase and during the following long term period, depending on the success of the stabilization of the tailings dam and the reduction of dangers to environment.

\subsection{Objectives of the Safety Program}

Facility inspections should be performed by the competent authorities at all phases of the its life cycle. The objectives and their realization have been outlined already in the previous text but a reiteration may serve to emphasize the steps required for their accomplishment and the importance of eliminating any risk to the environment or human health. 
One additional and important objective is to verify in particular if the tailings is managed in accordance with the applicable legal and regulatory standards, as well as with the approved operation manual and waste management plan. The objectives are, therefore;

(i) Verification that the chosen location for the waste facility is going well with its performance and agrees with the assumed factors affecting its design and its construction.

(ii) Verification that the physical stability of the waste facility is ensured and that pollution or contamination of soil, air, surface water or groundwater are prevented.

(iii) Verification of the adequacy of the regular monitoring of emission and emission measurements.

(iv) Verification if failures were properly reported and proper corrective action was taken.

(v) Verification that the physical stability of the waste facility is ensured.

(vi) Verification of the rehabilitation process is done well, including its proper documentation, and finally,

(vii) If the management of the tailings facility does not follow the operation manual and/or waste management plan; whereby in such case, the governing authority should urge the operator to introduce corrective actions within a specified period, and if this is not done, to withdraw back the operation permit [15].

\subsection{Procedures of Carrying Out the Safety Monitoring Program}

The safety monitoring program is normally carried out in well-established and defined routines in important tailings facilities. It is done through; visual inspections by the facility engineers and preferably with participation from the designer staff, and by the periodic reading, recording and analyzing of instruments networks, and performing various measurements and tests in which the designer should also take part, and finally appraisal of the dam safety by the designer in safety reviews based on the accumulated data in the past years. If a critical condition appears at any time during this period, then this justifies carrying out an immediate safety review by the designer, and recommended actions are to be implemented to restore the required level of safety; this is explained in the following;

A Visual Inspections

Visual inspections normally aim at looking for, and discovering of, at an early stage, cracks, evidence of any leakage, saturated areas and wet spots, appearance of springs, piping, erosion, sinkholes, slumping, frost heave, deviations in crest alignment, bulging or changes in slopes and depression of berms. Moreover, the drainage system has to be checked for any possible obstructions or damage by potential chemical reactions or bacterial growth. Sources of seepage, if any, have to be located and the rate and quality of water must be checked, while seepage volume 
is measured and related to the progress in height of the rising tailings pond level. All ancillary structures have to be checked for proper operation.

The frequency of visual inspections has to be decided by the designer at the start and may be changed by him during the service life, but an annual inspection is the normal practice and it shall cover all parts of the storage facilities; the dam, the pond and all ancillary works. If the tailings dam has been subjected to recent earthquake, then all after effects must be immediately noted and investigated and all damages recorded and appraised immediately not waiting for the routine inspection after finding out the magnitude of the event and its epicenter.

Every inspection shall be proceeded by appraisal of the previous inspection report in order to check if previous recommendations have been performed, and if not why. The inspection has to follow a prepared and updated checklist including all items to be seen or measured. Findings of the visual inspection have to be compiled in a report but if any anomaly is observed then this has to be reported immediately. The inspection report has to include description of the methods used for measurements, summary of findings and recommendations for further actions and has to be supported by drawings and photographic documentations.

\section{Use of Monitoring Instrumentation}

Performance monitoring by the use of instruments is an important way to determine if all structures are behaving as anticipated by the design. Doing this includes installation and use of such instruments as to observe the development of pore water pressure in the dam body, variation of phreatic surface level within it, settlement, displacements and deformations in the fill, and if the dam is located in seismic region then provisions must be made for measuring strong motion parameters at the site and dam's response. While the readings of these devices is done on regular basis predetermined by the designer, their adequacy and proper functioning have to be checked also according to fixed schedules. Some dam Safety Regulation Authorities specify two years as a normal period for doing this.

\section{Dam Safety Review Studies}

Regulating authorities normally require, from time to time dam safety review reports submitted to them by the management as a condition for continuing the validity of the operation permit of the facility. The report of any such study must state in clear way the safety level of the tailings dam and pond, and that it does not pose any threat to third parties. Such report is compiled by the designer and shall be based on analyzing all the data and information made available to him from the previous safety inspections and instrumentations readings and measurements. Such reports take special weight after the occurrence of an accidents; in such a case, it must include full description of the accidents, its most probable reasons and its impact on the safety of operations. It shall also describe all the repair works, and any other works, that were performed to upgrade the safety level to the acceptable standards.

Recommendations to owners and operators who have specific responsibilities to apply safety management procedures to achieve safety improvement and risk 
reduction are to carry out the following actions which draw heavily on safety observation and monitoring.

(i) Detailed site investigation by experienced geologists and geotechnical engineers to determine possible potential for failure, with in situ and laboratory testing to determine the properties of the foundation materials.

(ii) Application of state of the art procedures for design.

(iii)Expert construction supervision and inspection.

(iv)Laboratory testing for "as built" conditions.

(v) Routine monitoring.

(vi) Safety evaluation for observed conditions including "as built" geometry, materials and shearing resistance. Observations and effects of piezometric conditions.

(vii) Dam break studies.

(viii) Contingency plan.

(ix)Periodic safety audits. Regulatory Authorities should be more concerned about the safety of tailings dams that come under their jurisdiction and should require periodic reviews carried out by appointed specialists. In some countries approval had to be obtained for specific stages of construction, causing the stability, general condition and safety to be automatically checked from time to time [16].

\subsection{Comparison of Basic Requirements for Tailings Dams vs. Conventional Dams}

Tailings dam surveillance must serve three vital functions of:

(i) Confirm that the dam is safe, and is performing in accordance with design criteria and objectives.

(ii) Confirm design assumptions, and adjust the ongoing design and construction of the dam as necessary based on observations less favorable than design assumptions, or optimize design and construction based on observations more favorable than design assumptions.

(iii) Clear identification of failure modes capable of detection by the surveillance program, and those not capable of detection, so as not to lead to complacency with regards to the latter.

The continuity of works in tailings dams over the whole life of the project and the nature of the purpose and methods of construction make these dams different from conventional dams in so many aspects Although the need for preserving high safety levels is common for both, surveillance requirements may differ. Table 3 shows a comparison between the two types requirements. 
Table 3: Tailings dams vs. conventional dams in terms of surveillance requirements.

\begin{tabular}{|c|c|c|}
\hline Conventional dams & Tailings Dams & $\begin{array}{l}\text { Implications for tailings dam } \\
\text { surveillance program }\end{array}$ \\
\hline $\begin{array}{l}\text { Construction occurs in a } \\
\text { single stage, followed by } \\
\text { operation under steady state } \\
\text { conditions. }\end{array}$ & $\begin{array}{l}\text { Construction occurs on a } \\
\text { regular, near-continuous } \\
\text { basis. Steady state is not } \\
\text { achieved until closure }\end{array}$ & $\begin{array}{l}\text { The conditions of the dam and the } \\
\text { loadings to which the dam is subjected, } \\
\text { and therefore surveillance requirements, } \\
\text { are constantly changing. There is no } \\
\text { opportunity to "relax". }\end{array}$ \\
\hline $\begin{array}{l}\text { Constructed and operated by } \\
\text { organizations experienced } \\
\text { and focused on dam } \\
\text { operation and surveillance. }\end{array}$ & $\begin{array}{l}\text { Constructed and operated } \\
\text { by organizations whose } \\
\text { focus and expertise is in } \\
\text { extracting wealth from } \\
\text { the ground, not in } \\
\text { building dams. }\end{array}$ & $\begin{array}{l}\text { Operations personnel require training, } \\
\text { support, and commitment from corporate } \\
\text { to mine management level. }\end{array}$ \\
\hline $\begin{array}{l}\text { Typically owned by state or } \\
\text { large utility with substantial } \\
\text { financial resources to apply } \\
\text { to dam safety. }\end{array}$ & $\begin{array}{l}\text { Economics of mining } \\
\text { limit the resources that } \\
\text { can be applied in } \\
\text { construction and } \\
\text { operation of the dam. }\end{array}$ & $\begin{array}{l}\text { Tailings dam owners must resist the } \\
\text { inevitable temptation to cut back on } \\
\text { surveillance program in favor of devoting } \\
\text { more resources to profit centers. } \\
\text { Resources applied to surveillance must } \\
\text { be independent of cyclical business } \\
\text { environments. }\end{array}$ \\
\hline $\begin{array}{l}\text { Viewed as a significant asset } \\
\text { (generates revenue) by the } \\
\text { owner and, typically, by the } \\
\text { public which derives direct, } \\
\text { tangible benefit from the } \\
\text { dam. }\end{array}$ & $\begin{array}{l}\text { A cost center for the } \\
\text { mining operation, a } \\
\text { "necessary evil", and } \\
\text { understandably not the } \\
\text { focus of the operation. } \\
\text { Definitely not viewed as } \\
\text { an asset by the public }\end{array}$ & $\begin{array}{c}\text { As above, tailings dam owners must } \\
\text { resist the obvious and understandable } \\
\text { temptation to reduce resources available } \\
\text { for dam surveillance. Must not just } \\
\text { practice due diligence, but be seen to be } \\
\text { doing so to reassure regulators and the } \\
\text { public. }\end{array}$ \\
\hline $\begin{array}{l}\text { Owners generally have } \\
\text { inhouse dam engineering } \\
\text { expertise, including } \\
\text { personnel whose sole } \\
\text { function is surveillance. }\end{array}$ & $\begin{array}{l}\text { Typically, no in-house } \\
\text { dam engineering } \\
\text { expertise, reliance on } \\
\text { consultants. Dam } \\
\text { surveillance is not a } \\
\text { career path for miners. }\end{array}$ & $\begin{array}{l}\text { Disconnect exists between those carrying } \\
\text { out the surveillance program (operators) } \\
\text { and the dam engineering expertise } \\
\text { required to evaluate the results of the } \\
\text { program (consultants). Continuity of } \\
\text { advice, and clear communications } \\
\text { essential. }\end{array}$ \\
\hline $\begin{array}{l}\text { Have a finite operating life, } \\
\text { do not have to last "forever". }\end{array}$ & $\begin{array}{l}\text { Have a closure phase as } \\
\text { well as operational phase, } \\
\text { have to last "forever". }\end{array}$ & $\begin{array}{l}\text { Most tailings dams will require some } \\
\text { degree of surveillance "forever", } \\
\text { particularly so for the increasing number } \\
\text { of water retaining tailings dams being } \\
\text { used to keep sulfide tailings submerged. }\end{array}$ \\
\hline
\end{tabular}


In spite of the different goals and methods of construction, tailings dam surveillance requires all activities necessary for achieving safety and continuity of service similar to conventional dam, and should include all of the ingredients as in conventional dams i.e. determination of the data that needs to be gathered to confirm satisfactory performance, design of a surveillance program that will obtain the required data, with a suitable level of redundancy (repeatability), training of those personnel responsible for collection of the data as to how to obtain and manage the data and to provide awareness as to warning signs, provision of the installations and resources required in the form of instrumentation, time, personnel, access to permit responsible personnel to carry out the program, maintenance of the installations such as but not limited to piezometers, inclinometers, seepage weirs required to carry out the program and establishing a level of "respect" for installations within all on-site personnel to avoid, for example, damage to critical installations by vehicle traffic.

It is most important in tailings dams' operations to present at all times data in the form of plot of piezometer level vs. time, and water levels including trigger levels to allow for quick and effective interpretation and response. Prior definition of warning signs and response plans are to be enacted in the event that warning signs are noted. Due to the need for quick response in emergencies clear and documented lines of communication and responsibility in terms of data gathering, plotting, reporting, and action are needed [17].

In tailings dams, maintenance of reasonable safety standard is the joint work of the owner, operators, designers, safety reviewers, and the regulators, but contrary to conventional dams it requires much deeper way of public participation. It requires the recognition of the vital importance of the mining industry to modern society and to the economies of developing countries, and that elimination of mining must eventually mean a return to a Paleolithic lifestyle. It requires also continual of responsible stewardship of the environment by this essential industry and the acknowledgment that the vast majority of mining industry operators and operations deserve praise for their efforts [18]. 


\section{Tailings Dams Failure and the Need for Instrumentation, Measurements and Observations}

Understanding of the failure modes of tailings dams is very important step in assessing their safety, and it requires prior understanding of what can go wrong and what input data are required. Such data may only be obtained from visual observations, instruments recording, measurements and laboratory testing which all form a complete safety monitoring program. In the following a brief description of failure modes is presented, so that the required measurements and types of instruments needed are to be indicated later on;

\section{Rotational failure}

Rotational failures can range from local sloughing of tailings at random areas along the face of an embankment to massive circular arc slides extending over the entire structure. In general, for a stable slope, the shear strength resisting movement along a potential failure surface exceeds the shear stress tending to induce movement. Instability occurs when the shear stress on the failure surface equals the shear strength. Specifically, causes of rotational failure may include changes in the water table, changes in the permeability of the foundation materials, disturbances to the embankment caused by vibration or impact loading, settlement of the foundation materials, etc.

\section{Foundation failures}

Foundation failures are not uncommon among earthfill structures. Where a weak layer of soil or rock exists at shallow depth in the foundation below the structure, movement along a failure plane will occur if the earthfill loading produces stresses in excess of the shear strength of the soil in the weak layer.

\section{Overtopping}

One of the most common causes of failure is overtopping by flood waters. Overtopping typically results when the volume of run-on entering an impoundment, from improper diversion of surface water flows or excessive stormwater flow, exceeds the capacity of the impoundment. Because tailings embankments are constructed of highly erodible materials, the friction caused by rapid flow over an unprotected embankment crest may quickly erode a gully in the fill material, allowing sustained release to occur. Additionally, a rapid increase in pore pressure associated with large stormwater inflow may result in the liquefaction of unconsolidated impounded sands and slimes. Sustained high flow over the crest of an embankment can thus result in a major failure of the overall impoundment within minutes.

\section{Erosion}

In areas of heavy rainfall, some form of protection against erosion is usually required. Tailings embankments may be susceptible to erosion failure in two major areas, embankment abutments and the embankment face. Erosion along the contact line between the embankment and the abutment may result from stormwater flow that concentrates there. Typically, this type of failure is preventable with proper stormwater diversion methods and so results from faulty design or maintenance. 
Erosion of embankment faces may result from rupture in tailings pipe lines installed on the embankment crest. Again, maintenance and alternate siting of tailings lines may prevent this type of failure.

\section{Piping}

Piping refers to subsurface erosion along a seepage pathway within or beneath an embankment which results in the formation of a low-pressure conduit allowing concentrated flow. Piping may result also from seepage exiting the face of an embankment with sufficient velocity to erode the embankment face. The resulting void space promotes progressive erosion extending upstream toward the source of the seepage. In the worst case, the seepage may result in the creation of a direct channel from the tailings pond to the dam face Excessive piping may result in local or general failure of the embankment or the embankment foundation.

\section{Liquefaction}

Liquefaction is one of the most common failure modes of cross-valley dams. Because tailings deposits typically comprise unconsolidated, saturated deposits of similarly-sized grains, they are susceptible to temporary suspension in water Liquefied tailings may behave like a viscous fluid, such that they may pass through narrow openings and flow considerable distances. Accordingly, even small dam failures may result in substantial releases of tailings flow.

\section{Safety Parameters and Use of Instrumentation}

In the following paragraphs, the main parameter contributing to the safety of tailings dams are presented with description of the methods, ways and means used in safety monitoring programs;

\section{a) Dam saturation line monitoring}

One common practice to monitor the saturation line or phreatic surface level variation in the embankment, and therefore conditions of pore pressure, is to use open pipe piezometers. The pore water pressure regime in a tailings dam, or any other earthfill dam for that matter, has a significant influence on the stability of the dam wall. Single standpipe piezometers at various cross sections around a tailings dam, is commonly used to monitor the pore pressure in the area close to the outer wall. Typically, piezometers data is recorded on a monthly basis and used in stability analyses. Once a base case analysis has been carried out, further analyses are usually only carried out once significant changes occur in the piezometric values are recorded. Sometimes, other piezometers in the form of pore pressure measuring cells are used. Two types of this sort are available; the first is the diaphragm type, where a diaphragm is placed between the transducer and the pore water. This is a pneumatic vibrating wire, or electrical resistant strain gauge; the second type is a standpipe without diaphragm and uses twin tubed hydraulic construction which is known in literature as the Casagrande type piezometer.

The construction of standpipe piezometer consists of porous filter element at the tip so that the instrument responds to subsurface water pressure around the filter element and not the fluctuations at other elevations. The water level in the stand 
pipe stabilizes at the piezometric elevation and is determined by sounding with a probe which is normally electric dip meter.

In such case, the water level recorded in single standpipe piezometer cannot measure the fluctuation of the phreatic surface and therefore such variation can only be obtained from multiple number of such piezometers installed in the same cross section and having their tips at different elevations [23].

Following the measurements of phreatic surface using piezometers helps to indicate the safety stability status of the dam and leads to executing remedial measures to improve the safety conditions.

According to Swedish dam safety guidelines, the factor of safety in terms of slope stability of tailings dams should be at least 1.5 under normal conditions. In order to prevent the factor of safety to be lower than 1.5 , strengthening actions are needed for the dam. In actual study case, rockfill embankment was added at the downstream toe, and in order to optimize the amount of rockfill, the rockfill support plan was followed by site measurements of the phreatic surface elevation by the installed piezometers and calculating the stability conditions of the dam. Figure 3 indicates the measured phreatic water surface before the addition of the rockfill berm and the location of slip surface in the dam. Figure 4 on the other hand shows the actual conditions after construction of the embankment.

Since the safety of the dam is maintained even though excess pore water pressures exist, a proposed alert level is therefore the limit where hydrostatic pore water pressure is exceeded. The hydrostatic pressure is here based on a phreatic line at the tailings surface. If the pore water pressure measured at site is lower than this alert level, the measurement is said to be in the green stage. The factor of safety is higher than 1.5 in the green stage, while the yellow stage the stability is ensured even with some excess pore pressure, but stability has to be observed with caution. Passing this stage into the red stage would be intolerable and has to be prevented, which is schematically shown in Figure 5 [24]. 


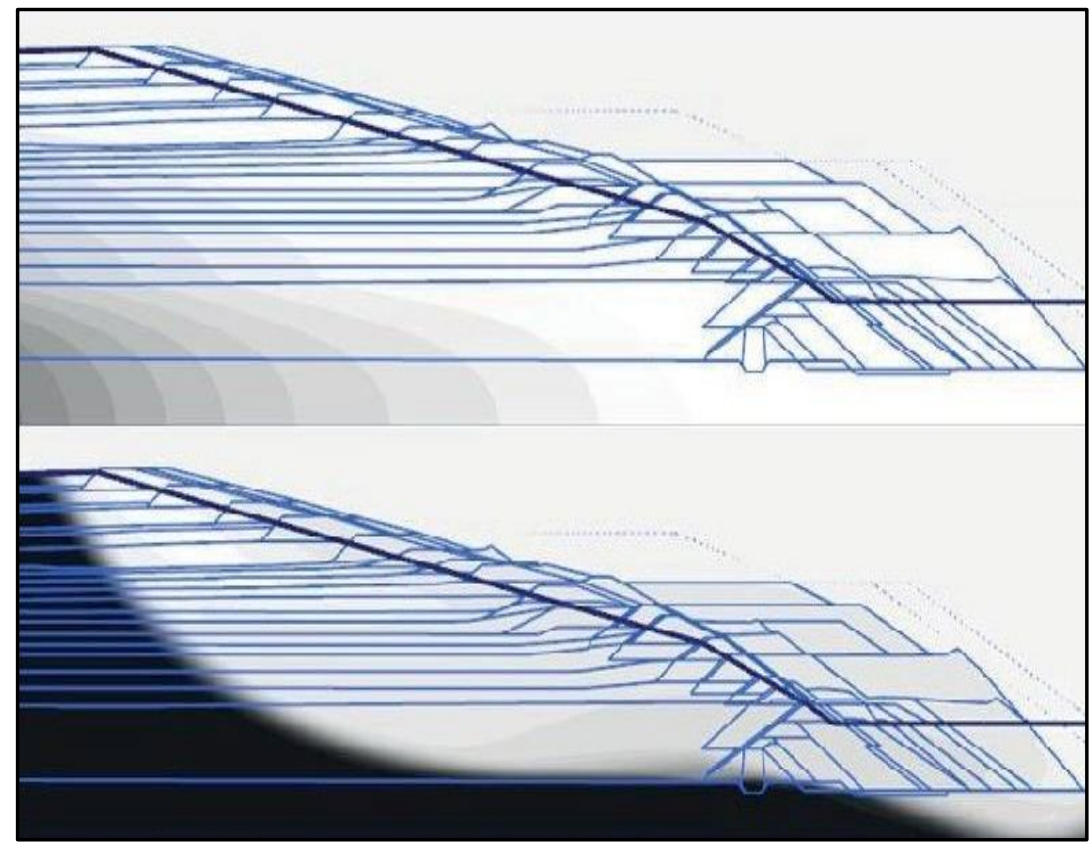

Figure 3: Before embankment construction 2015.

Upper: Simulated excess pore pressure. Lower: Most probable slip Circle (Factor of Safety 1.58) [24].

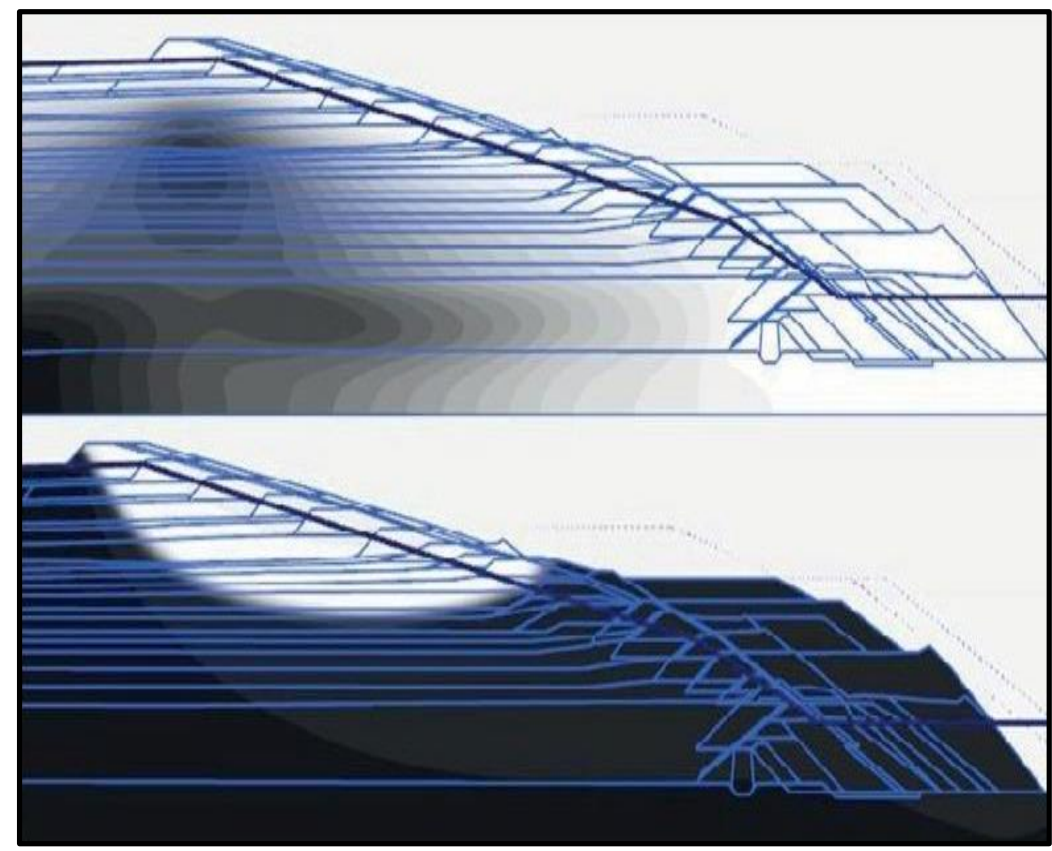

Figure 4: After embankment construction 2015.

Upper: Simulated excess water pressure. Lower: probable slip surface (factor of safety 1.49) [24]. 


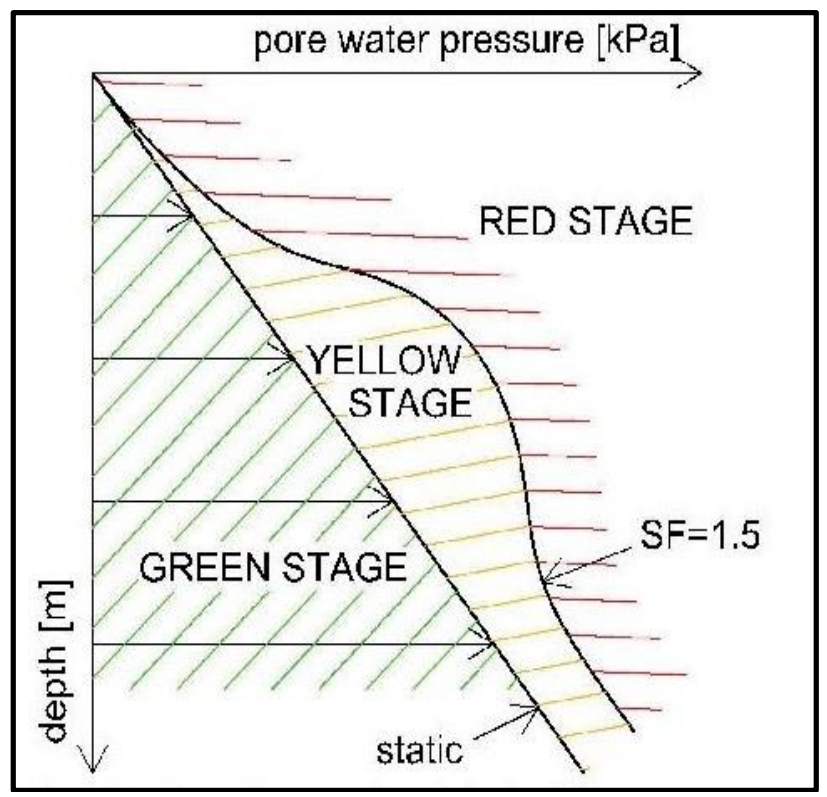

Figure 5: Schematic presentation of alert levels for pore water pressure. (The three alert stages are, green, yellow and red) [24].

\section{b) Water Levels Monitoring}

One of the most critical parameters for the safe operation of tailing dam is water level control, not only of water level in the pond but also of surface water and the water table underneath the dam. Monitoring the level of surface water can give an early indication if there are sudden rising levels due to floods, rain or ice melt. A radar level transmitter is a great fit for this type of application. When it comes to the water table, it is done by installing hydrostatic level sensor in piezometers.

With regard to the maximum safe water level in the pond, its determination during the design stage is important to avoid overtopping of the tailings dam which can lead to its failure and release of dangerous waste.

Normally, the minimum safe freeboard is determined by national/local legislation and/or company policies. It is essential in the design stage that water balance calculations consider average and extreme conditions to prevent loss of freeboard during operation which may result in overtopping. 
Freeboard management, and pond water level monitoring are critical factors for the control water of both conventional and tailings storage impoundments [25]. To promote good drainage of the embankments, the supernatant pond has to be as far away from the embankments as possible and maintain a high freeboard and wide beach. Ideally the pond should be of a small area, to reduce seepage, and be at a maximum depth at the decant facility to improve reclaim water clarity. Figure 6 shows examples of loss of freeboard and high freeboard.

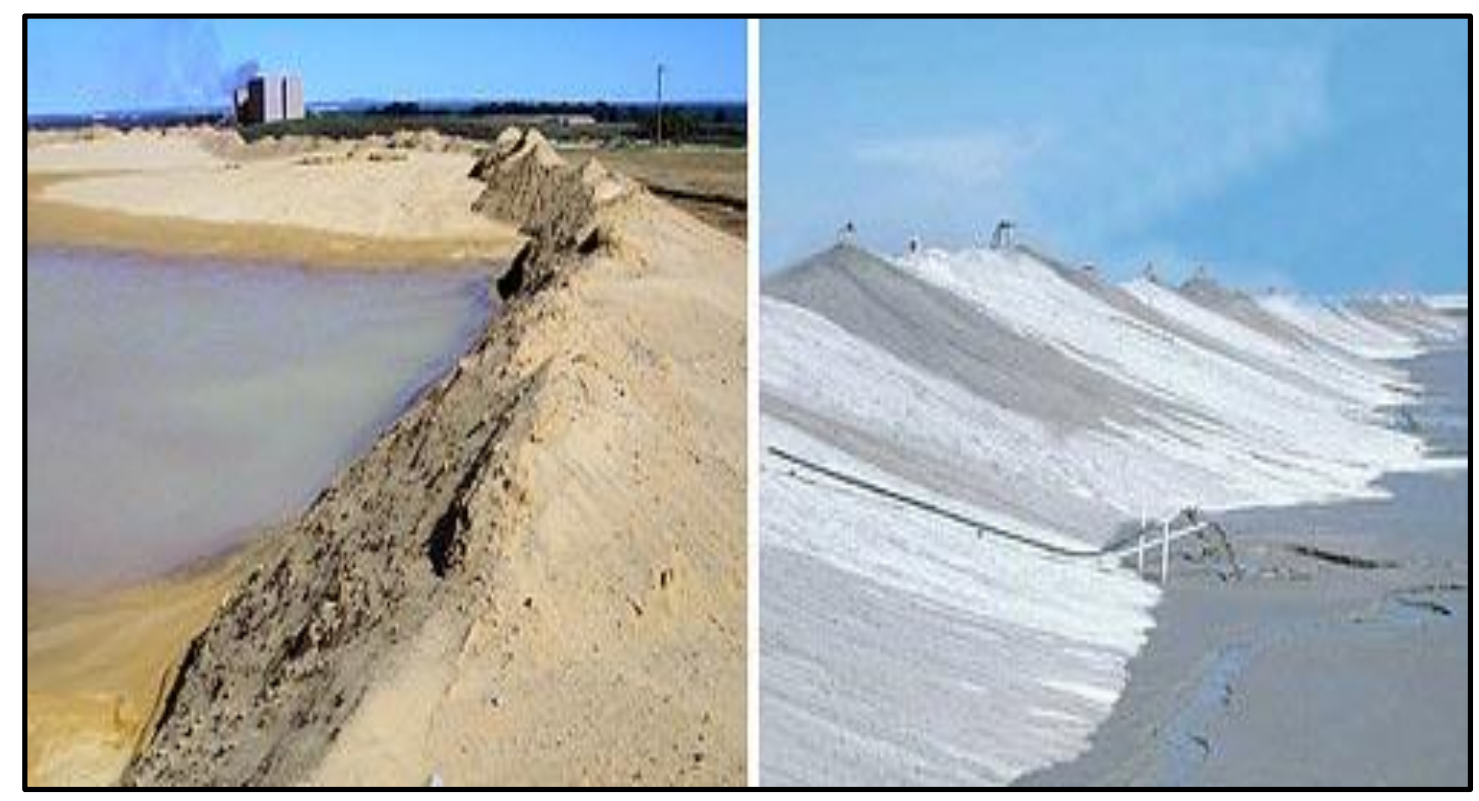

Figure 6: Loss of freeboard (left), and high freeboard (right). () Jon Engels, Right picture courtesy of Anglo American) [25].

The diagrams shown in the following Figure 7 explain the definitions related to freeboard in possible conditions of the pond. 


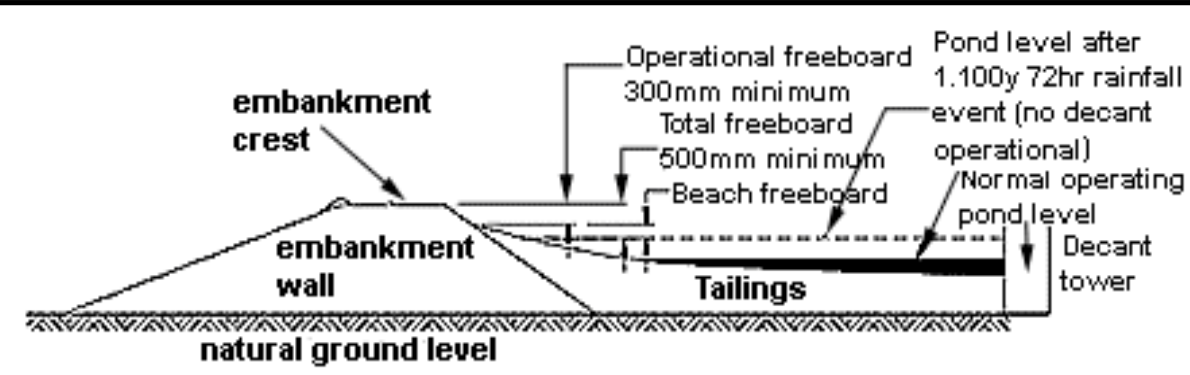

For case where pond is located away from amy perimeter embankments

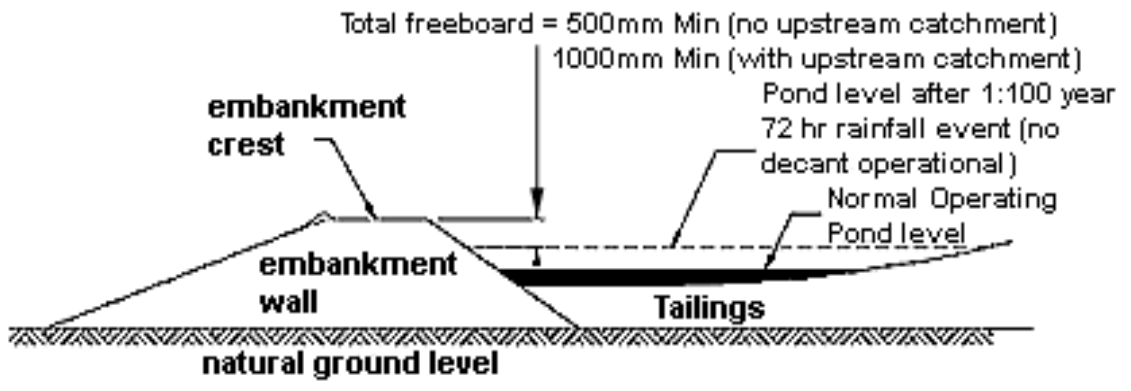

For case where pond is located against perimeter embankments

Figure 7: Freeboard of a tailings facility explained. (Adapted from (DME 1999) (C Jon Engels) [25].

Freeboard loss can lead to overtopping which leads in its turn to the rapid failure of the tailings dam, such loss may result from damaged diversion spillway or blockage or misjudgment of the actual water level and wrong design criterial. As shown in Figure 8, checking of the spillway conditions and has to be done, tailing pond water level has to be monitored continuously by installing water level sensors and sounding devices. Real time measurement, recording and telemetering on continuous basis instrumentations are available and for large facilities their high cost is justified [26]. 


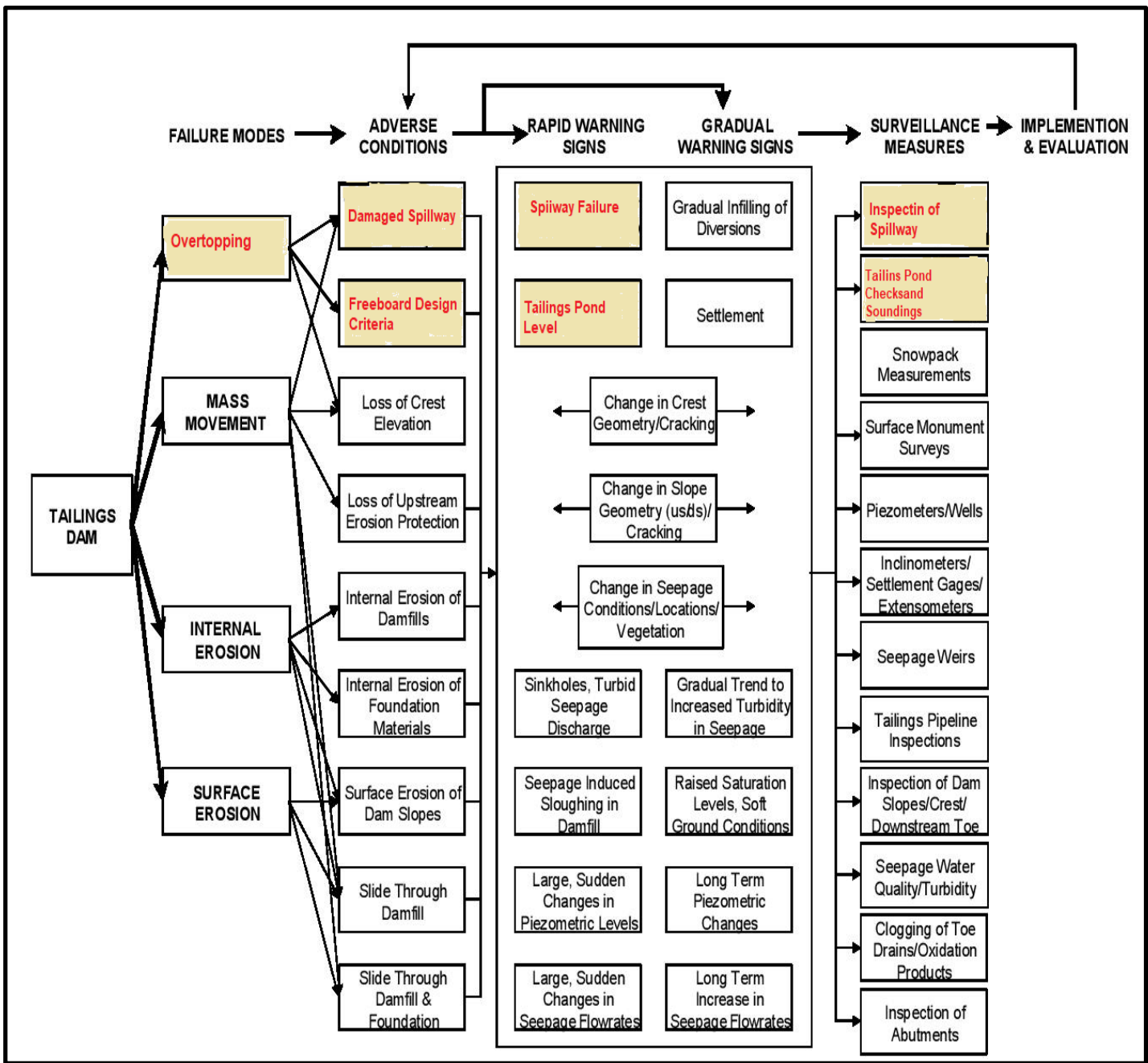

Figure 8: Overtopping mode failure path, explained. Inspections of spillway and tailing pond plus checking and monitoring water level indicated (All in yellow color) [26]. (Figure modified by the writer).

Modern technologies are available today for monitoring precisely tailings pond level by installing a complete system assembly on a barge that floats on the pond and connected to the embankment by a bridge.

An actual example provided with real-time monitoring capabilities and powered by solar energy is used now by a Canadian oil sands mining company and it is illustrated in Figure 9.

In this system, cellular data communications is used to provide connectivity to site (RTU) and to a (SatSCADA) server. Differential (GPS) transceiver (DGPS) and Radar Level Sensors (RLS) are used to achieve required accuracy and to provide the correct (GPS) level of the Barge.

A Radar Level Sensor (RLS) is connected to data logger which is used to measure the distance to the water line. The (RLS) distance combined with the (GPS) 
reference level is used to calculate the exact water level. All data is sent periodically back up to the (SatSCADA) server for archival, trending and display. Users access the data is done via (SatSCADA) web client which can provide access through to laptop, desktop, tablets, and smartphones.

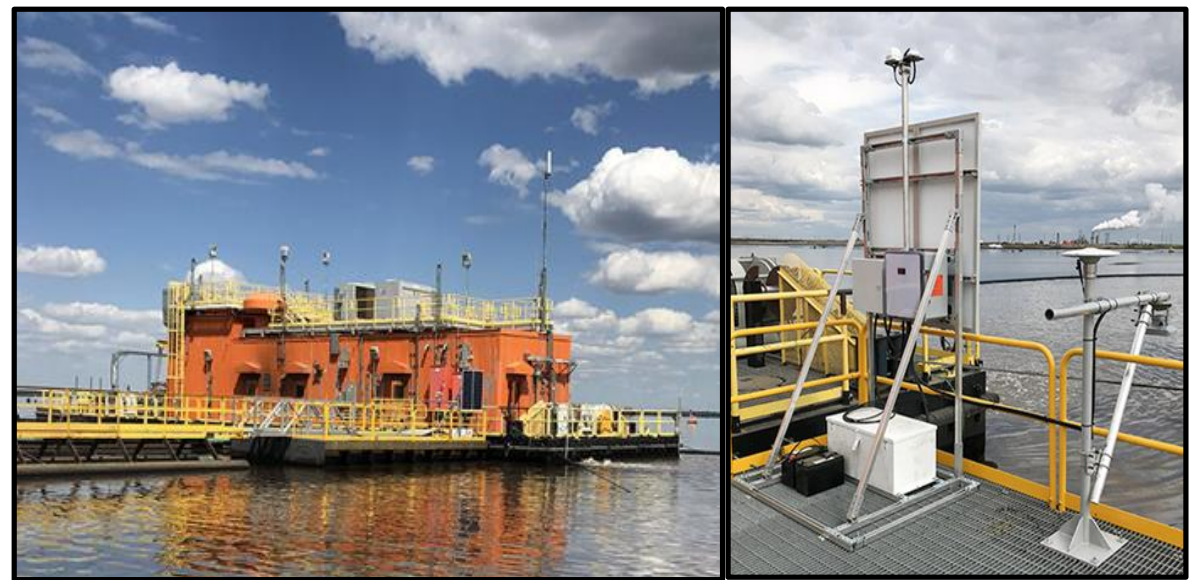

Figure 9: Left: view of the barge.

Right: The sensor and transmission arrangement.

\section{c) Seepage Outflow Discharge Measurements}

All seepage water should be collected, and the discharge measured by weirs of Vnotch, rectangular or trapezoidal type. Calibrated containers might be used to measure low discharges.

Seepage discharge is the most important factor which has to be measured in respect of dam stability and it can provide evidence of any serious failure in tailings dams. It is indicative of internal erosion in the dam body with grave consequences if all the necessary measures are not taken in due time. This measurement should be automated and the readings recorded without interruption in the control room. It is appropriate to register separately the discharge coming out from each drain and place, so as to be able to determine more easily the location of any increase of seepage and the possible occurrence of erosion.

It is essential for tailings dams to be well drained, to keep the phreatic surface as far away as possible from the downstream slope, to reduce pore pressure and to decrease the danger of liquefaction. The drainage augments the seepage discharge which is much greater than in earthfill dams. However, it is not dangerous if there are properly functioning filters and drains, and if the seepage quantity is collected and turned back to the tailings pond or the processing plant.

Observational data from several operating tailings dams indicate that flow nets may be used to estimate seepage flows and to determine the location of the phreatic surface through the beach and tailings dam with sufficient accuracy for most design purposes. The greatest unknown is the effective permeability of the tailings beach and it is recommended that the maximum probable values for both the permeability and the permeability ratio $(\mathrm{kmax} / \mathrm{kmin})$ be used for all computations. This 
procedure will produce conservatively high values for both the seepage quantity and the location of the phreatic line.

Seepage control measures unquestionably add to the total costs of the tailings storage facilities. However, they greatly increase the overall safety of the tailings dams and when properly designed and constructed satisfy both the safety and pollution control requirements of the regulatory agencies. The additional costs associated with constructing adequate seepage control measures should be considered a necessary part of the cost of building and operating a mine in today's society [28]. Needless to say, that if this is coupled with good observation and monitoring procedure will enhance the safety conditions and avoid surprises due to unaccounted conditions

\section{d) Seepage and Drainage Water Quality Measurements}

The environment can be affected by mining operations in numerous and reactive ways. The production of Acid Mine Drainage (AMD) and contaminated seepage water caused by oxidation of the sulfide minerals in the presence of water is probably the main threat to many ecosystems. AMD is recognized as a multi-factor pollutant; the main factor being acidity, toxicity, suspended solids and salinization. One of the main goals of tailings water management is to ensure that water quality in surrounding bodies of water is not degraded by drainage and seepage water generated from tailings ponds. To that end, some manufacturers can offer both stationary and portable water sampling stations in full compliance with all relevant national and international standards. Such sampling and the following measurements can help in deciding on the best suited technology for treatment, size of treatment plants to be used before returning the collected affluent to the environment.

The chemical composition of tailings seepage and drainage water is important in determining any potential environmental impacts. Factors include waste characteristics such as mineralogy of the host rock and milling methods used to produce the tailings, and the interaction of the tailings seepage with the liner, if any, and the subsurface. Contaminant mobility can be increased by physical mining processes such as milling, whereby, a small grind results in increased surface area for leaching. Most mining companies manipulate $\mathrm{pH}$ and use chelating agents to extract minerals from the ore. These same processes can be applied to the fate and transport of contaminants in tailings. While many heavy metals are hydrophobic with strong adsorption tendencies for soil, the chemical reagents used in mining processes may be present in the tailings material. They are able to remove the metals, making them mobile in leachate or surface waters.

Contaminated water may be formed from downward migration of impoundment constituents or ground water movement through tailings. Most contaminant transport in ground water systems is from the advection i.e. fluid movement and mixing of contaminants. The geochemistry of the aquifer, physicochemical properties of the tailings and seepage will determine the buffering capacity of the soil, types of chemical reactions, whether in precipitation or neutralization, and the 
rate of adsorption and ion exchange.

A related problem is the production of acid by oxidation of thiosalts, which is a problem for some metal mines in eastern Canada. The bacterial culprit is thiobacillus thiooxidans. Thiosalts may be removed from the mill effluent by biological treatments [29].

In all the aforementioned details, a clear indication of the need for measurement of tailings affluent quality is recognized. This is considered as the first step towards their amelioration and removing the contamination threat they pause to the environment.

\section{e) Inflow Water Control Measurements}

Measuring what goes in the tailing ponds is the first step in responsible tailings management. Measuring the flow of the ore slurry is not enough. However, the solids content of the slurry can also be found and the relation between solids and water calculated.

By using an electromagnetic flowmeter, one can measure both parameters with just one instrument. When it comes to quality measurement, digital analytical sensors can tell which substances are entering the tailings. Such flowmeter mounted on delivery pipes to the tailing pond is shown in Figure 10 [30].

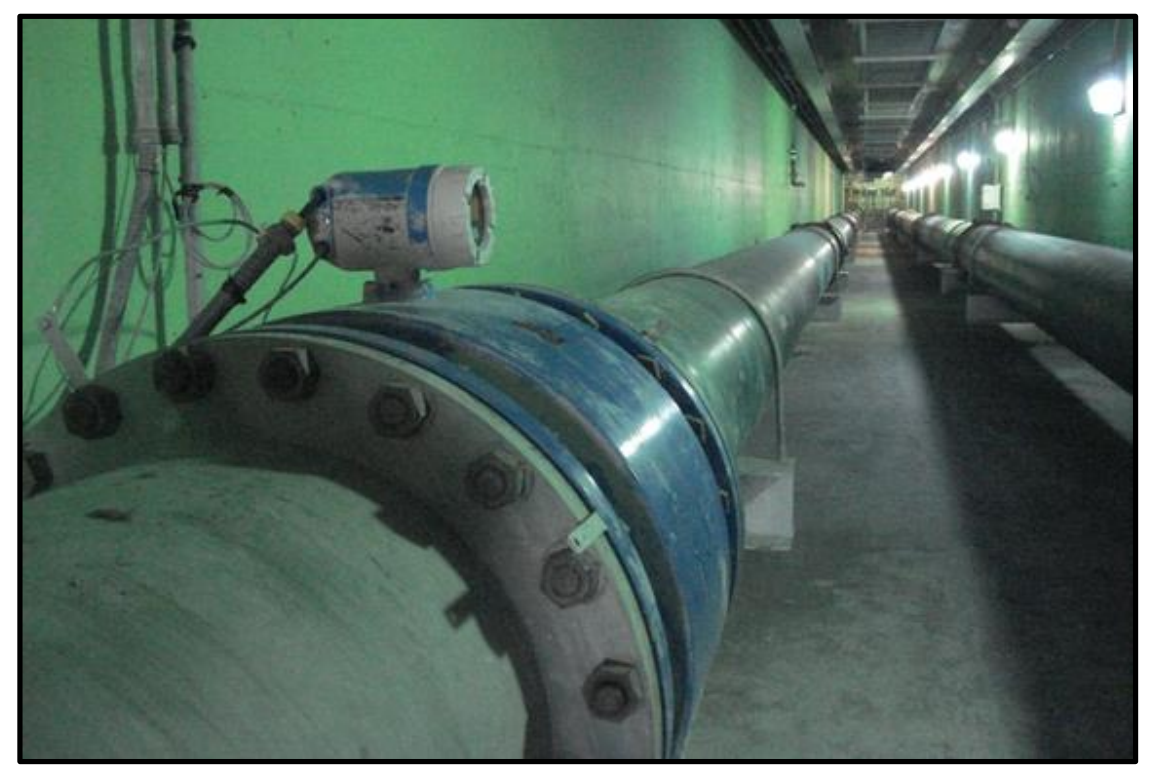

Figure 10: Endress and Houser type electromagnetic flow meter [30]. 


\section{f) Monitoring the Vertical Displacement of the Dam}

Vertical movements in tailings deposits are large and are due to compaction from its own weight and to consolidation. The external movements are measured by means of a survey control pillars and geodetic datum points network. The control points or pillars are placed sufficiently outside the dam to avoid the influence of dam weight. The geodetic monuments are provided in sufficient numbers and are located along the crest of completed stages, berms of the downstream slope, along the crest of completed tailings dam and on the beach of completed dam.

Monitoring the vertical displacement of the dam can also be done by vibrating multi-variable testing meter, using a vibrating wire displacement sensor as a measuring head. The measuring head, through a fiber glass rod and anchor head, are connected according to design requirements at different depths in the borehole and the surrounding soil with its mobile sensor and can measure vertical displacements at different levels [31].

\section{g) Horizontal displacement monitoring}

In tailings dams, the external horizontal movements are due mainly to non- uniform settlement of different parts and much less to pressures from retained water. They are measured at same geodetic positions used for surveying the vertical movements. More exact measurements can be performed when the points are located in one straight line and the movements are measured in relation to it. If the dam crest and berms are not in straight lines, less accurate trigonometric methods can be used. Methods in this case are the optical clinometers or the sophisticated laser instruments. Careful study of successive sets of stereoscopic aerial photographs can reveal horizontal movements that have occurred, and may be particularly used for checking a long dam.

Within the body of the dam horizontal movement can be detected by inclinometers. Inclinometer is installed in a pipe string. Layer and structure movement cause inclinometer displacement and force the inclinometer tube to deform from the initial position to a new location. Inclinometer sensor measures the rake and from its deviation from its original slope displacement can be obtained. Inclinometer tubes are embedded from the bottom of the deepest starting point of each segment and it reflects the displacement of soil at that level.

The horizontal movement of a deformable foundation can be measured with inclinometers or inverted pendulum, and may be used absolutely for the starter dam due to their high cost. Use of GIS is also justified for use in large tailings dams.

Large movements are not so dangerous if they are distributed over large areas and if their rate decreases with time, on the contrary, small movements can be dangerous if they are concentrated at one place and if their rate increases with time.

Generally speaking, high precision deformation measurement can be done using GPS precision positioning technology, compared with classical measurement, this cannot only meet precision requirement (within $\pm 1 \mathrm{~mm}$ ) of dam deformation monitoring, but also help to realize automation of monitoring work. For instance, in order to monitor the dam deformation, technicians select a GIS Continuously 
Operating Reference Stations (CORS) and a number of monitoring points in deformation area far from appropriate position of dam. In the base station and management center, the technicians install GPS receivers respectively which carry out continuous automatic observation. By using proper data transmission technology, monitoring data is real-time transferred to data processing center to carrying out treatment, analysis and prediction of observation data, Figure 11 [31].

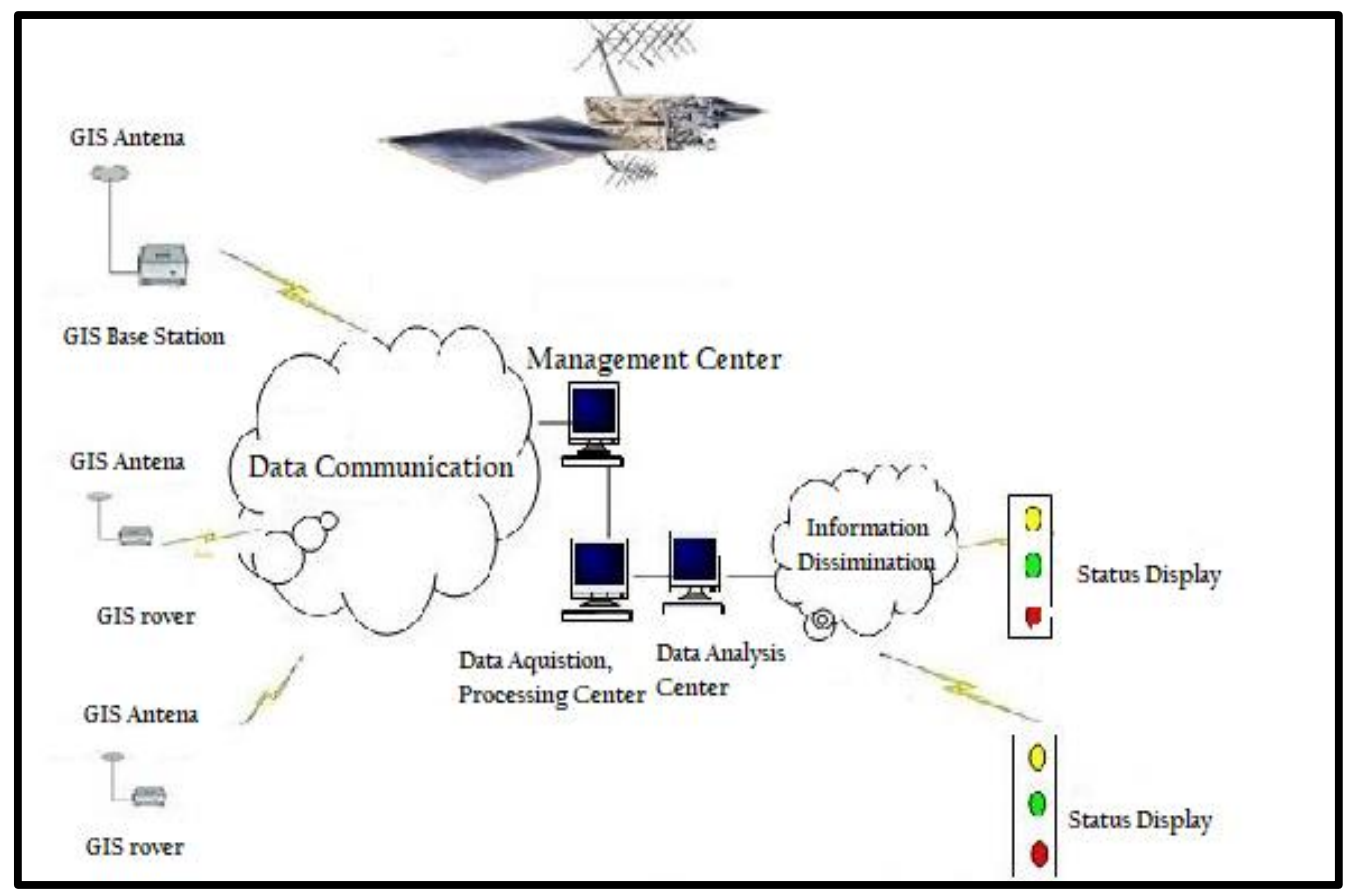

Figure 11: Structure of GIS System [31].

The precision of the horizontal displacement and vertical displacement, obtained by using precision broadcast ephemeris and $6 \sim 8$ hours dual-frequency GPS observations, is better than $1.0 \mathrm{~mm}$. Applied in building monitoring, GPS technology can not only be free from limitation under the intervisibility and climate conditions, which carry out all-weather monitoring in heavy fog and snowstorm conditions, but also can collect transmit and manage data, analysis deformation and automatically forecast. So, it can reach the purpose of remote online network realtime monitoring. Besides, GPS can still carry out dynamic deformation monitoring and export the result of real-time positioning according to $10 \sim 20 \mathrm{~Hz}$ frequency. Baseline vectors, produced by GPS relative positioning, can obtain high precision geodetic altitude by survey adjustment. As the vital observation here is the relative settlement during vertical displacement monitoring. We could, without conversion, directly use geodetic altitude system, which will not only simplify calculating work, but also ensure precision of observation results [32]. 


\section{h) Differential Settlement of embankment}

The differential settlement in the embankment can be measured with internal vertical movement measuring devices. Most suitable are PVC standpipes with settlement plates or rings made of stainless steel fitted over the pipes and an electromagnetic probe lowered in the standpipe, to measure the position of the plates. The plates are placed on the surface of the rising tailings, and spaced at certain vertical interval (most frequently about 5 meters). They are commonly $30-40 \mathrm{~cm}$ across, and move together with the settling tailings, sliding over the pipes.

Since the tailings suffer large settlements, it is not appropriate to use telescoping pipes which are applied in earthfill dams, because settlement plates may get stuck at the splicing. It is preferable to use tightly and smoothly spliced pipes to allow the plates to slide unhindered over the pipes.

Settlement devices are usually used to obtain the following information:

1. The compaction of the deposited tailings and its variation with time at different heights of the dam.

2. The settlement of the foundation. The measurement of settlement and pore pressure gives information about the consolidation of the tailings at full scale and provides in-suite data, supplementing any laboratory consolidation tests that had been made to obtain information for design. One can determine from them the deformation modulus and pore pressures coefficient $\left(r_{u}\right)$ for every layer, as a function of load and time. These functions are input data to give more reliable calculation of the stressstrain state and consolidation of the dam.

\section{i) Total pressure measurement}

The measurement of total pressure is used for three purposes;

1. to obtain the effective pressure, which is required for calculating the stability of the tailings dam. This is given by the total pressure, after subtracting from it the measured pore pressure.

2. The acting pressures on structures such as the decant towers or chutes, culverts etc. required in order to check design calculations and overall stability.

3. The total pressure in the horizontal and vertical directions to obtain the coefficient of total pressure and also Poisson's ratio, which can be assumed here as simple stress dependent.

For the total pressure measurement similar instruments as those used in conventional earthfill dams may be used also.

\section{j) Monitoring Seismicity}

Large tailings dams and particularly those located in seismic regions, require socalled "strong motion accelerograph" to register the stronger earthquakes above a certain given threshold, which can be varied at will, and it is usually $0.1 \mathrm{~g}$. As a 
minimum, two or three accelerographs should be used. One accelerograph which is the "main" or the "master", is placed on the bedrock, to first register the earthquake. It sends signals to a computer that controls the others, that are placed in shallow excavations at two different places in the upper part of the downstream slope. They are periodically moved during operation so as to be in the upper part of the slope, and after the tailings dam ceases to operate, they are placed on the beach in the tailings. They are used for determining the tailings damping response, required for calibrating the seismic numerical model and calculating the earthquake response of tailings dams.

Other than the dam, the mine open pit can also be monitored for micro-seismicity by accelerographs which are mounted in shallow holes on or near the top of the mine. An example is shown in Figure 12 of such instruments of SP2 type model used for monitoring micro seismicity of a mine open pit which is produced by Sure Wave Technology Ltd.

Such technology can be used to continuously monitor and detect micro-seismic events occurring within the slope walls of open cut mines and other surface material deposits such as tailings dams, giving advance warning of internal movement and the potential for collapse.

Each sensor can typically monitor micro-seismic activity up to a certain distance depending on the model used. The micro-seismic activity can be displayed on a 3D image and updated in real time. The micro-seismic events displayed are indications of stress build up within the side walls or dam structure with the potential to lead to a failure. In addition, water pore pressure variation can be mapped in real time to visualize what is happening inside the structure. For a dam, this may include pore water inside the tailings leading to movement of the base material in a liquefaction mode.

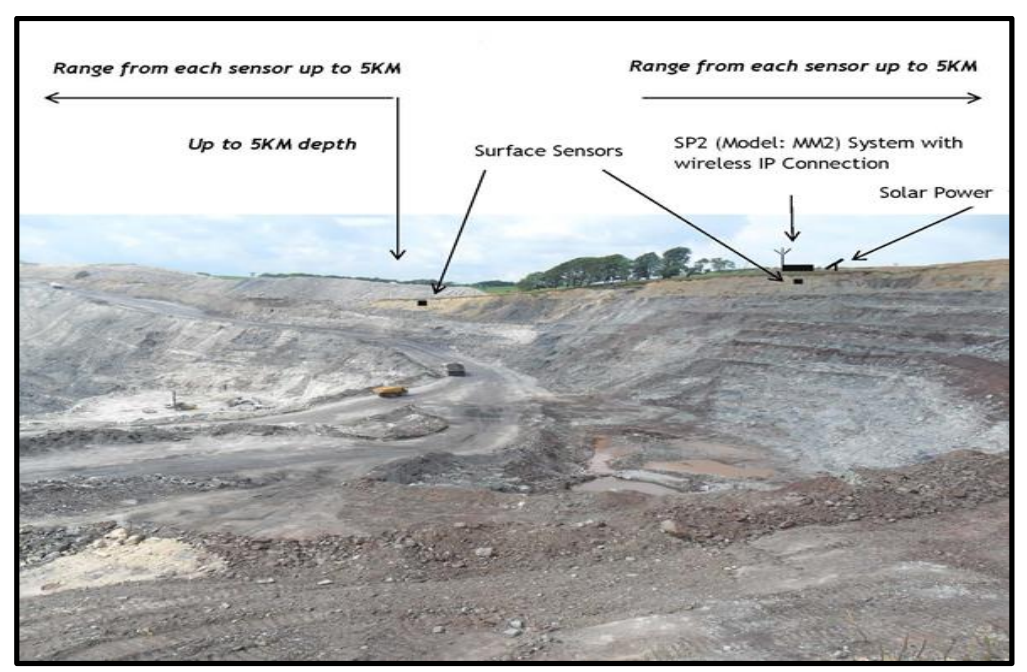

Figure 12: An example of micro-seismic accelerographs used for open pit and tailings dam monitoring (SureWave Technology Ltd.) [33]. 


\section{Value VS. Cost of Tailings Dams Monitoring Systems}

Tailings dams are more than 10 times more likely to fail than other conventional water retaining dams [34]. Operating a tailings dam involves risks that need to be identified, quantified and mitigated. These dams are subjected to many hazards that directly influence their stability, which need to be properly identified and assessed during both the dam construction stage and the following closure stage.

The main hazards potentially influencing the dam as to their likelihood and possible consequences are shown in a matrix form in Figure 13 [35].

\begin{tabular}{|c|c|c|c|c|c|}
\hline \multirow[b]{2}{*}{ Likelihood } & \multicolumn{5}{|c|}{ Consequences } \\
\hline & Insignificant & Minor & Moderate & Major & Severe \\
\hline Almost certail & & & & & \\
\hline Likely & M & & & & \\
\hline Possible & L & M & & & \\
\hline Unlikely & L & M & M & & \\
\hline Rare & L & L & M & M & $\begin{array}{l}\text { External } \\
\text { Geohazary }\end{array}$ \\
\hline
\end{tabular}

Figure 13: Main risks affecting directly the dam stability [35].

Need for monitoring and its extent comes naturally from the identified risks and need to mitigate safety conditions to prevent accidents and failures. So it follows that methods, types and extent of any safety monitoring program will be governed by the factors indicated in the aforementioned matrix.

Maintaining dam integrity requires ongoing focus on appropriate engineering design, quality construction and operating discipline. This is enabled through maintenance of the dam, good governance of its facilities; and may be followed through awareness of potential failure modes and continuous monitoring and surveillance followed by frequent safety reviews.

Need for a continuously running safety monitoring program is permanent throughout the whole life cycle of the tailings dam. The operational phase of any dam is dynamic and is likely to include expansion of the dam, raising of the dam height and/or addition of dams. The closure phase of a dam can often exceed in its duration the operational phase of the dam, yet it may need ongoing observation of 
seepage quantity and quality and their impact on surface and ground water, geochemical and physical changes that emanate from the inactive dam [36].

Failure of tailings storage facilities (TSF) can have disastrous consequences for nearby communities, the ecosystem, and for the mining companies, who may consequently face high financial and reputational costs.

The ecosystems impacts caused by any failure can last for many years depending on the nature of the tailings. As an example; In 2015, the breach of the Fundão Tailings Dam at Samarco mine in Minas Gerais resulted in 19 fatalities, and was declared the worst environmental disaster in Brazil's history. In settlement of the claims resulting from this failure, the owners had to agree on a settlement plan costing $\$ 2.4$ billion to remediate and compensate for the impacts over a 15 years. Moreover, twenty-one company executives were charged with qualified murder. In the above mentioned example, the owning company is in the process now of restoring 5,000 streams, 16,000 hectares of "Permanent Conservation Areas" along the Doce River basin, and1,200 hectares in the riverbanks. It is estimated that the livelihoods of more than 1 million people were affected because of the failure [37]. The costs of installing, running and maintaining tailings dam safety monitoring program can be high, but not so high if losses of similar magnitudes as in the above case are to result.

The cost of any safety monitoring program may increase if modern real-time logging and transmitting are introduced. But the total cost, should be, in any case, be commensurate with the number of required measurements, types of instruments to used, and the method of data logging which are all functions of the dam risks and the consequences magnitude.

The running cost the system monitoring program, whether during the active phase of construction or through the inactive phase of closure, adds up to the initial cost, and the total budget of the program has to include provision for the safety review studies to analyst the collected data by highly qualified and highly paid consultant. All these costs, however, can be justified in view of the large possible losses that the mining enterprise has to bear in case of failure. Any safety monitoring program can be, however, tailored according to the size of the tailing facility and is running operations.

In a great number of cases, the time value of money increases the pressure on private enterprise to maximize profits in the short-term.

Therefore, the required additional initial capital expenditure of installation and the ongoing cost of running an instrumented safety monitoring program may put these systems at disfavor, due to the continued managerial emphasis on deferring expenditure, promoting low-capital tailings disposal solutions with little emphasis on monitoring and rehabilitation costs. 


\section{Comments, Summary points and Conclusions}

8.1 In the past 20 years' statistics show an increasing trend in tailings dam failures. This may have been a result of adverse weather conditions due to climate change and poor management of very large mining facilities. Moreover, rapid dyke construction following the need to satisfy the rising demand of growing industries over the mined metals has probably contributed in many ways to this end. In cases of absence of sound management procedures Increasing safety requirements of dams and more awareness of their increasing threats to the environment and societies have contributed to the development of more advanced monitoring means and methods. Although systems of monitoring tailings storage facilities are more advanced than conventional dams, even more accurate and automated, they are still not absolutely reliable, and many catastrophic failures were reported during the last decades.

The current engineering practice in tailings dam design is based on conventional dams' design principles, in which the selection of the appropriate magnitude of design loading is governed by the potential consequences, and the higher the consequence the higher the design loads used. The increasing magnitude of design loads also significantly increases the level of uncertainties in the stability analysis, material characteristics, its performance and the design load parameters themselves. The unique nature of tailings dams introduces additional uncertainties, which do not exist in water dams [38]. These facts plus the recent dangerous occurrences involving tailings dams support the need for establishment rigid and continuous dam safety monitoring program during both of its service and closure life.

8.2 Published statistics of tailings dams' failures and incidents are limited compared to those which belong to conventional dams and only major catastrophes have been reported. Most accidents pass without notice, either due to the remote locations of the mines, or because of the owners' desire not to publicize such events and keep a clean image in the eyes of the public, or even because their main concern is to keep production going without interruptions. The modes of failures of tailing dams in these cases show that many such accidents could have been avoided with good and responsible managements supported by rigid and continuous routines of safety surveillance and safety reviews. As in conventional dams this is achieved by visual observation and measurements, use of recording instruments, and analyzing all the accumulated data by competent engineers to come up with recommendation for changes and upgrading works. Monitoring program for tailings dams is often included in a comprehensive "Operations Manual". Operations manual is a document required by legislation in an increasing number of jurisdictions [39]. However, due to the lack of clear monitoring guidelines, some of them are a result of internal rules, local conditions and needs. Most of the mining companies have developed their own guideline for tailings dam safety 
8.3 In spite of the different goals and methods of construction, tailings dams' surveillance requires all activities necessary for achieving safety and continuity of service similar to conventional dams, and should include all, and even more, of the ingredients as in conventional dams. Any useful safety monitoring program for tailings dams has to be a continuous chain of activities carried out in successive stages and extending over very long time which may last for decades. Dam safety programs for tailings dams differ from those applied in conventional dams in its duration. Such programs should cover the active life of dam construction, which goes on as long as the mine remains open for production, and its closure phase afterwards. Safety checks are normally comprised of routine visual inspection, use of recording instruments, performing various measurements, and so often use of automation to record and transmit the data to the control center for analysis and appraisal. Moreover, frequent safety reviews, carried out by professional engineers, have become mandatory requirement of Regulating Authorities in accordance with national legislations. Requirements of these legislation are normally commensurate with the risk category of the dam.

8.4 Recognition of the common failure modes of these dams show that they range between; rotational failures, foundation failures, overtopping, erosion of the slopes, piping and internal erosion, and liquefaction under seismic loading; which are also common in conventional earthfill dams. Parameters leading to these modes of failure include excessive rise of pond water level, high phreatic surface level and excess pore water pressure in the fill, development of seepages through fill and foundations, deformation of dam, settlement and differential settlement, total earth pressure and seismicity. Host of instruments, devices and methods for measuring and recording include, inflow discharge meters, piezometers, weirs, settlements plates, inclinometers, and geodetic surveys checking, while seismographs are important elements in any safety monitoring for dams especially in known aseismic active regions. Tailings dams offer very good opportunities for the use of modern real time measuring, transmitting and recording equipment in view of the large volume of such measurements and recordings required in very large facilities. In doing this, tailings enterprises, in spite of the high cost of such equipment, save a great deal in the cost of labor in a work which they consider not to fall in their mainstream activity. Moreover, such systems offer the opportunity of discovering an early threat before it is too late to interfere with repair or upgrading actions.

8.5 Major difference between conventional dams and tailings dams are the higher threats tailings dams present to the natural environment and the ecosystem. Most of the elements currently used in industrial applications, technology development, and energy generation are produced through the mining operations and disposal of the waste in tailings dams and ponds. Adverse changes in the landscape can result from the high demand of water and energy and the large quantities of mobile effluents associated with tailing production 
and disposal. Historically, this activity can be considered as one of the main anthropogenic activities that contribute to major and trace elements pollution of river basins worldwide, which may lead to serious human health implications and also long-term impairment to waterways and biodiversity. There are two serious problems usually associated with mining activities, the acid-mine drainage and the mine tailings that contribute deliberately and/or accidentally to the burden of anthropogenically derived metals to river basins. What differs tailing dam accidents from other anthropogenic activities is the amount and velocity which slurry may travels, covering soils, river sediments, floodplains, riverbanks, and damaging water quality and adversely impacting plant and animal life. Taking all this into consideration warrants looking into the question of establishing a good and robust safety monitoring program seriously. Any cost- benefits analysis of such program should be based on the assessment of the risks involved in tailing spills due to accidents or complete failures. Investments in such program have to be matched against the high costs of compensations, rehabilitation and restoration of the damaged environmental which many take generations after the closure phase. In summary establishing and running such a program is highly recommendable, and it may be considered as part of the insurance cost of the safe running and management of this industry. 


\section{References}

[1] ICOLD (2001). Tailings Dams-risk of dangerous occurrences, lessons learnt from practical experiences. Bulletin 121, ICOLD and UNEP Publication. http://www.unep.fr/shared/publications/pdf/2891-TailingsDams.pdf

[2] Berghe, J. F. V., Ballard, J. C., Pirson, M. and Reh, U. (2011). Risks of tailings dams' failure. Proceedings of the 3rd International Symposium on Geotechnical Risk and Safety (ISGSR), Vol.2, No.3, p.6, Munich, Germany, June 2011.

https://izw.baw.de/e-medien/geotechnical-safety-and-risk2011/PDF/3\%20Risk\%20and\%20Reliability\%20in\%20Geotechnical\%20Eng ineering/3_03.pdf.

[3] Azam, S. and Li, Q. (2010). Tailings Dam Failures: A Review of the Last One Hundred Years. Waste Geotechnics Geotechnical News, December 2010. https://pdfs.semanticscholar.org/e57e/bdac0a801b412cefd42017c2dded29caf d41.pdf?_ga=2.76418966.2044964655.15929902121325417008.1592236244

[4] Palu, M. C. and Julien, P. Y. (2019). Review of Tailings Dam Failures in Brazil. XXIII Simpósio Brasileiro de Recursos Hídricos (ISSN 2318-0358), 24 December 2019. https://www.researchgate.net/publication/337498009_REVIEW_OF_TAILI NGS_DAM_FAILURES_IN_BRAZIL .

[5] Ricoa, M., Benitob, G., Salguero, A. R., Diez-Herrerod, A. and Pereir, H.G. (2008). Reported tailings dam failures. A review of the European incidents in the worldwide context. Journal of Hazardous Materials 152(2):846-52 DOI: 10.1016/j.jhazmat.2007.07.050 . Available from:

https://www.researchgate.net/publication/5985618_Reported_tailings_dam_f ailures_A_review_of_the_European_incidents_in_the_worldwide_context

[6] Shiqiang, H., Lawrence, C. and Colin, C. (2017). Real-time monitoring for structural health, public safety, and risk management of mine tailings dams. Canadian Journal of Earth. Submitted by the Author on 22nd Nov 2017 Manuscript ID cjes-2017-0186.R1.

https://tspace.library.utoronto.ca/bitstream/1807/82538/1/cjes-2017-0186.pdf.

[7] Natural Resources Canada (2015). National Building Code of Canada seismic hazard maps. Retrieved on 25th June 2020.

https://earthquakescanada.nrcan.gc.ca/hazard-alea/zoningzonage/NBCC2015maps-en.php.

[8] Szymanski, M. B. and Davies, M. P. (2004). Tailings Dams Design Criteria and Safety Evaluation at Closure. DOI:10.14288/1.0042456 Corpus ID: 112815136, or https://pdfs.semanticscholar.org/59af/35f2fe69d82ef4258b911f7b421966e91 07d.pdf?_ga=2.10817463.2044964655.1592990212-

1325417008.1592236244 
[9] Niemeläinen, E., Juvankoski, M., Kaartinen, T., Laine-Ylijoki, J., Merta, E., Mroueh, U., Mäkinen, J., Punkkinen, H. and Wahlström, M. (n.d.). Dams: Water management-Dams at mine closure phase. VTT Technical Research Centre of Finland, Finland. Retrieved on 25th June 2020. https://mineclosure.gtk.fi/dams/

[10] Solismaa, L. (n.d.). Monitoring of Tailings Dams. Geological Survey of Finland, Finland. Retrieved on 25th June 2020. https://mineclosure.gtk.fi/monitoring/

[11] Bligh, G. E. and Fourie, A. B. (n.d.). A Review of Catastrophic Flow Failures of Deposits of Mine Waste and Municipal Refuse. University of the Witwatersrand, Johannesburg, South Africa.

https://www.researchgate.net/publication/242193591_A_REVIEW_OF_CAT ASTROPHIC_FLOW_FAILURES_OF_DEPOSITS_OF_MINE_WASTE_A ND_MUNICIPAL_REFUSE

[12] Smith, E. and David, H. (1979). The Role of Water in the Failure of Tailings Dams. Proceedings of First International Mine Drainage Symposium-mine drainage, pp.627-649. Denver, Colorado, USA, 1979.

https://www.imwa.info/imwaconferencesandcongresses/proceedings/193proceedings-1979.html,or

http://www.imwa.de/docs/imds_1979/IMDS1979_Smith_627.pdf

[13] Lyu, Z., Chai, J., Xu, Z., Yuan Qin, Y. and Jing Cao, J. (2019). A Comprehensive Review on Reasons for Tailings Dam Failures Based on Case History. Hindawi Advances in Civil Engineering, Vol.2019, pp.1-18. http://downloads.hindawi.com/journals/ace/2019/4159306.pdf

[14] Hui, S., Charlebois, L. and Colin Sun, C. (2018). Real-time monitoring for structural health, public safety, and risk management of mine tailings dams. Canadian Journal of Earth Sciences, 55 (3): 221-229. https://www.researchgate.net/publication/321894917_Realtime_monitoring_for_structural_health_public_safety_and_risk_management _of_mine_tailings_dams.

[15] U N. Economic Commission for Europe (2014). Safety guidelines and good practices for tailings management facilities. Report, chapter B4, p.24. New York Geneva 2014 https://www.unece.org/fileadmin/DAM/env/documents/2014/TEIA/Publicati ons/1326665_ECE_TMF_Publication.pdf.

[16] ICOLD-UNEP (2001). Tailings Dams Risk of Dangerous occurrences Lessons learnt from practical experiences. Bulletin 1212001. https://www.academia.edu/9168393/RISK_OF_DANGEROUS_OCCURRE NCES.

[17] Martin, T. E. and Davies, M. P. (n.d.). Development and Review of Surveillance Programs for Tailings Dams. AGRA Earth \& Environmental Limited, Burnaby, $\mathrm{BC}$ http://citeseerx.ist.psu.edu/viewdoc/download?doi=10.1.1.520.7963\&rep=rep $1 \&$ type=pdf. 
[18] Martin, T. E., Davies, M. P., Rice, S., Higgs, T. and Lighthall, P. C. (2002). Stewardship of Tailings Facilities. Concluding Remarks, Mining, Minerals and Sustainable Development Project, International Institute for Environment and Development (IIED), p.32. B.C., Canada April 2002. https://pubs.iied.org/pdfs/G01027.pdf.

[19] ICOLD-UNEP (2001). Risk of Dangerous occurrences-Lessons Learned from Practical Experiences. Bulletin 121, pp.23-25, 2001. https://www.academia.edu/9168393/RISK_OF_DANGEROUS_OCCURRE NCES.

[20] U.S Environment Protection Agency (1994). Technical Report: Design and Evaluation of Tailings Dams, pp.36- 38. Washington DC, August 1994. https://archive.epa.gov/epawaste/nonhaz/industrial/special/web/pdf/tailings.p df.

[21] Grotowski, A. (2010). Current practice in tailings ponds risk assessment. Cuprum Nr.2 (55) pp.15, 34-39.

https://ia801601.us.archive.org/35/items/CurrentPracticeInTailingsPondsRisk Asse Grotowski ssment/Cuprum\%2022010_Current\%20practice_Pytel_Str\%205-42_.pdf

Or,https://archive.org/details/CurrentPracticeInTailingsPondsRiskAssessment ?q=Pit+slope+manual\%2C+waste+embankments.

[22] Macorra, C. (n.d.). Design and Evaluation of Tailings Dam. Hasanuddin University, Mining Engineering, Graduate Student, pp.36- 46. https://www.academia.edu/21652018/DESIGN_AND_EVALUATION_OF_ TAILINGS_DAMS.

[23] Le Roux, G. J. R. (2002). The effectiveness of single and multiple open standpipe piezometers in monitoring of pore pressure in tailings dams. Proceedings of the 9th International Conference on Tailings and Mine Waste, pp.35-38. Fort Colins, Colorado, USA 27-30 January 2002.

https://books.google.se/books?id=PPTL9-

$1 \mathrm{M} 78 \mathrm{AC} \& \mathrm{pg}=\mathrm{PA} 35 \& \mathrm{lpg}=\mathrm{PA} 35 \& \mathrm{dq}=\mathrm{Dam}+$ phreatic+surface+level++monito ring+in+tailing+dams\&source $=$ bl\&ots $=5 \mathrm{z} 2 \mathrm{gkarY}$ vi\&sig $=$ ACfU3U1d3VM9F Drp5HHu7u7tyZm9b7D0DA\&hl=sv\&sa=X\&ved=2ahUKEwifsKTM55_qA hXCw6YKHcmgAd8Q6AEwAHoECAoQAQ\#v=onepage\&q=Dam\%20phre atic\%20surface $\% 20$ level $\% 20 \% 20$ monitoring $\% 20 \mathrm{in} \% 20$ tailing $\% 20 \mathrm{dams} \& \mathrm{f}=\mathrm{f}$ alse

[24] Knutsson, R. (2015). Tailings Dam Performance Modeling and Safety Analysis of a Tailings dam. MSc thesis , p.37, Luleå University of Technology, Luleå, November $2015 \quad$ Sweden.http://www.divaportal.se/smash/get/diva2:991090/FULLTEXT01.pdf

[25] Tailings.info (n.d.). Water Management Considerations for Conventional Storage- Freeboard. A tailings storage and handling resource. Retrieved on 1st July 2020. https://www.tailings.info/technical/water.htm. 
[26] Martin, T. E. and Davies, M. P. (n.d.). Development and Review of Surveillance Program for Tailings Dam. Figure (3), AGRA Earth \& Environmental Limited, Burnaby, BC. http://citeseerx.ist.psu.edu/viewdoc/download?doi=10.1.1.520.7963\&rep=rep $1 \&$ type=pdf.

[27] Bentek Systems (2018). Tailings Pond Level Monitoring System Using Differential GPS and Radar Level Sensor. 06-06-2018. Retrieved on 2nd July 2020.

https://www.scadalink.com/blog-post/tailing-pond-level-monitoring-systemimplemented-using-differential-gps-and-radar-level-sensor/.

[28] Klohn, E. J. (1979). Seepage Control for Tailings Dams. IMDA 1979, Section 4, Tailings and Waste Disposal-Seepage, Contamination, Regulations, and Control,p.722.

https://www.imwa.info/docs/imds_1979/IMDS1979_Klohn_671.pdf.

[29] U.S. Environmental Protection Agency (1994). Technical Report "Design and Evaluation of Tailings Dams". Technical Report pp.44-45. August 1994. https://archive.epa.gov/epawaste/nonhaz/industrial/special/web/pdf/tailings.p df.

[30] Endress and Houser (n.d.). Reduce environmental risks by monitoring mining tailings and surface water. Retrieved on 2nd July 2020. https://www.se.endress.com/sv/industrier/mining-minerals-metals/Tailingswater-management.

[31] Hu, J. and Liu, X. (2011) Design and implementation of tailings dam security monitoring system. Procedia Engineering 26, pp.1915- 1916. Elsevier 2011. Available online. https://www.researchgate.net/publication/271560782_Design_and_Implemen tation_of_Tailings_Dam_Security_Monitoring_System

[32] Li, W., and Wang, C. (2011). GPS in the Tailings Dam Deformation Monitoring. First International Symposium on Mine Safety Science and Engineering, December 2011. Procedia Engineering 26 (2011):1648-1657. https://www.researchgate.net/publication/271581655_GPS_in_the_Tailings_ Dam_Deformation_Monitoring

[33] Sure Wave Technology Ltd., (n.d.). Tailings Dam and Side Wall Monitoring. Retrieved on 3rd July 2020.https://www.surewavetechnology.co.uk/minemonitoring/mine-monitoring-surface/

[34] Dams Lemphers (2010). Could the Hungarian tailings dam tragedy happen in Alberta? https://www.pembina.org/blog/could-hungarian-tailings-dam-tragedyhappen-alberta). 
[35] Vanden Berghe, J. F., Ballard, J. C., Fugro, M., P. and Reh, U. (2000). Strong Ground Motion characteristics of the Chi-Chi, Taiwan earthquake of September 21, 1999. Earthquake Engineering and Engineering Seismology, Vol.2, No.1, March 2000, pp.1-21. [https://izw.baw.de/e-medien/geotechnical-safety-and-risk2011/PDF/3\%20Risk\%20and\%20Reliability\%20in\%20Geotechnical\%20Eng ineering/3_03.pdf

[36] BHP (2019). Tailing dams. https://www.bhp.com/-/media/documents/media/reports-andpresentations/2019/190607_esgbriefingtailingsdams.pdf?la=en

[37] Adamo, N., Al-Ansari, N., Sissakian, V., Laue, J. and Knutsson, S. (2020). Dam Safety: The question of Tailings Dams (in the Print) (24) (PDF). Design of dams for mining industry. Accessed Jul 03, 2020, available from: https://www.researchgate.net/publication/331983101_Design_of_dams_for_ mining_industry.

[38] Michael, P. D., Peter, C., Lighthall, S. R. and Todd, E. M. (2002). Design of Tailings Dams and Impoundments. Keynote Address Tailings and Mine Waste Practices SME, AGM Phoenix, 2002 . 2002http://w3.cenn.org/cenn_projects/BfW_mining/Training/Managing $\% 20$ Effects\%20of\%20Major\%20Mines/Reference\%20Materials/Tailing/Design\% 20of\%20Tailings\%20Dams\%20Davies2002b.pdf P 13) 